\title{
Chemical composition of essential oils of eight Tunisian Eucalyptus species and their antibacterial activity against strains responsible for otitis
}

Elaissi Ameur ${ }^{1 *}$, Moumni Sarra', Derbali Yosra', Khouja Mariem², Abid Nabil ${ }^{3,4}$, Frederic Lynen ${ }^{5}$ and Khouja Mohamed Larbi

\begin{abstract}
Background: The chemical composition and biological activity of Eucalyptus essential oils have been studied extensively (EOs). A few of them were tested for antibacterial effectiveness against otitis strains. The chemical composition and antibacterial activity of the EOs of eight Tunisian Eucalyptus species were assessed in the present study.

Methods: Hydrodistillation was used to extract EOs from the dried leaves of eight Eucalyptus species: Eucalyptus accedens, Eucalyptus punctata, Eucalyptus robusta, Eucalyptus bosistoana, Eucalyptus cladocalyx, Eucalyptus lesouefii, Eucalyptus melliodora and Eucalyptus wandoo. They are assessed by GC/MS and GC/FID and evaluated for antibacterial activity using agar diffusion and broth microdilution techniques against three bacterial isolates (Haemophilus influenzae, Haemophilus parainfluenzae, Klebsiella pneumoniae) and three reference bacteria strains (Pseudomonas aeruginosa, ATTC 9027; Staphylococcus aureus, ATCC 6538; and Escherichia coli, ATCC 8739). Furthermore, the selected twenty-one major compounds and all values of the inhibition zone diameters were subjected to further statistical analysis using PCA and HCA.
\end{abstract}

Results: The EO yields of the studied Eucalyptus species range from $1.4 \pm 0.4 \%$ to $5.2 \pm 0.3 \%$. Among all the species studied, E. lesouefii had the greatest mean percentage of EOs. The identification of 128 components by GC (RI) and GC/MS allowed for $93.6 \%-97.7 \%$ of the total oil to be identified. 1,8-cineole was the most abundant component found, followed by $a$-pinene, $p$-cymene, and globulol. The chemical components of the eight EOs, extracted from the leaves of Eucalyptus species, were clustered into seven groups using PCA and HCA analyses, with each group forming a chemotype. The PCA and HCA analyses of antibacterial activity, on the other hand, identified five groups.

Conclusion: The oils of E. melliodora, E. bosistoana, and E. robusta show promise as antibiotic alternatives in the treatment of otitis media.

Keywords: Eucalyptus, Essential oils, Chemical composition, Antibacterial activity, Otitis, Principal Component Analysis (PCA), Hierarchical Cluster Analysis (HCA)

\footnotetext{
*Correspondence: aelaissi@yahoo.fr

${ }^{1}$ Chemical, Pharmacological and Gallenic Development Laboratory,

University of Monastir, Faculty of Pharmacy, Avenue Avicennne,

5000 Monastir, Tunisia

Full list of author information is available at the end of the article
}

(c) The Author(s) 2021, corrected publication 2021. Open Access This article is licensed under a Creative Commons Attribution 4.0 International License, which permits use, sharing, adaptation, distribution and reproduction in any medium or format, as long as you give appropriate credit to the original author(s) and the source, provide a link to the Creative Commons licence, and indicate if changes were made. The images or other third party material in this article are included in the article's Creative Commons licence, unless indicated otherwise in a credit line to the material. If material is not included in the article's Creative Commons licence and your intended use is not permitted by statutory regulation or exceeds the permitted use, you will need to obtain permission directly from the copyright holder. To view a copy of this licence, visit http://creativecommons.org/licenses/by/4.0/. The Creative Commons Public Domain Dedication waiver (http://creativecommons.org/publicdomain/zero/1.0/) applies to the data made available in this article, unless otherwise stated in a credit line to the data. 


\section{Background}

The genus Eucalyptus L'Herit., native to Australia, belongs to the Myrtaceae family and has around 900 species and subspecies [1]. The leaves of over 300 species in this genus produce volatile oil. The oil yields extracted from Eucalyptus leaves were reported to range from $0.06 \%$ to $7.0 \%[2,3]$. The pharmaceutical and cosmetic industries have economically exploited less than 20 species of essential oil (EO) rich in 1,8-cineole (>70\%) [4]. Natural medicine has sparked a surge of interest in recent years, particularly those employed to combat microbial agents, as numerous strains have exhibited resistance to pharmacological chemicals $[5,6]$. Drug resistance is found in Gram negative bacteria such as Escherichia coli, Klebsiella pneumoniae and Pseudomonas aeruginosa, as well as Gram positive bacteria like Staphylococcus aureus [7-10]. Drug resistance has led researchers to design novel antimicrobial compounds to treat a variety of human infections [9, 11-14]. Inhalation of EOs extracted from Eucalyptus sp. has traditionally been utilized in Tunisian folk medicine to treat respiratory tract illnesses such as pharyngitis, bronchitis, and sinusitis [15]. The ear is connected to the upper respiratory tract by a mucous membrane that connects the nose and throat. Streptococcus pneumoniae, Haemophilus influenza, Moraxella catarrhalis, Staphylococcus aureus, Haemophilus parainfluenzae, Escherichia coli, Pseudomonas aeruginosa, and Klebsiella pneumoniae have all been found to invade the mucous membrane [16-21]. A variety of respiratory diseases have been associated with these bacterial strains, including acute otitis media (AOM), sinusitis, asthma, and pneumonia [17-21]. Furthermore, several of these bacterial strains, including $P$. aeruginosa and $S$. aureus, as well as $K$. pneumoniae and other microorganisms, are responsible for otitis externa [22]. Every year, the AOM affects over $11 \%$ of the world's population (about 700 million individuals) [23]. The majority of them (51\%) are children under the age of five [24]. It's worth emphasizing that 31 million AOM patients, including more than 7 million children per year, are at risk of developing chronic suppurative otitis media (CSOM) [25]. Hearing loss can occur in more than half of CSOM patients [26, 27]. Although EOs derived from numerous Eucalyptus species have been shown to have antibacterial, antiviral, antioxidant, anti-inflammatory, and antiasthmatic activities [28-30], Few studies have explored the antibacterial activities of EOs against otitis pathogens. We described and investigated the biological activity of EOs isolated from the leaves of 60 Eucalyptus species collected from six arboreta in Tunisia in earlier works [7, 31-39]. The aim of the present study is to determine the variability of the yield, the chemical composition, and the antibacterial activities of EOs extracted from leaves of 8 Eucalyptus species. The antibacterial properties of microbial strains responsible for otitis are of special interest.

\section{Methods \\ Plant material}

We used clean mature leaves from eight species of Eucalyptus L'Hér. collected in June, 2017 from the following two regions: i) Eucalyptus accedens Fitzg., Eucalyptus robusta Sm. and Eucalyptus punctata DC. acclimated in Choucha arboretum and located in Sejnane region $\left(37^{\circ} 03^{\prime} 23^{\prime \prime} \mathrm{N}, 9^{\circ} 14^{\prime} 18^{\prime \prime} \mathrm{E}\right)$ in the North West of Tunisia, which belongs to the humid inferior bioclimatic stage with mild winter; ii) Eucalyptus melliodora A.Cunn. ex Schauer, Eucalyptus lesouefii Maiden, Eucalyptus cladocalyx F. Muell, Eucalyptus bosistoana F. Muell., and Eucalyptus wandoo Blakeley were collected from the Mjez Elbab arboretum in the North West of Tunisia $\left(36^{\circ} 38^{\prime} 55^{\prime \prime} \mathrm{N}, 9^{\circ} 36^{\prime} 45^{\prime \prime} \mathrm{E}\right)$, which belong to the upper semiarid bioclimatic stage with moderate winter.

The leaves were collected from three Eucalyptus trees, dried on an airy basis, protected from light, packed in paper bags, and stored in the shade. Botanical voucher specimens have been deposited at the Herbarium of the Faculty of Pharmacy's Pharmacognosy laboratory (Monastir, Tunisia) under the following numbers: 0173, 0174, 0175, 0176, 0177, 0178, 0179, 180.

\section{Extraction of essential oils}

The EOs were extracted using a standard apparatus specified by the European pharmacopoeia [40] by hydrodistilling $100 \mathrm{~g}$ of roughly crushed leaves for $4 \mathrm{~h}$. For each sample, hydrodistillation was carried out in triplicate. The EOs were collected and dried with $\mathrm{Na}_{2} \mathrm{SO}_{4}$ before being stored at $+4{ }^{\circ} \mathrm{C}$ until analysis. The EO yield was calculated as a percentage (\%) of the dry weight $(\mathrm{v} / \mathrm{w})$.

\section{GC analysis}

The EO extracts were analysed subsequently by GC and GC/MS in triplicates. GC analysis was carried out with a Hewlett-Packard 6890 apparatus equipped with FID and apolar HP5 cap. column. The remaining experiment parameters are as follow: the oven temperature (temp.) was programmed at $60{ }^{\circ} \mathrm{C}$ for $1 \mathrm{~min}$, rising gradually from $60{ }^{\circ} \mathrm{C}$ to $250{ }^{\circ} \mathrm{C}$ at $3{ }^{\circ} \mathrm{C} / \mathrm{min}$, and then held isother$\mathrm{mal}$ at $250^{\circ}$ for $3 \mathrm{~min}$; injector temp. at $250^{\circ} \mathrm{C}$; detector temp. at $280{ }^{\circ} \mathrm{C}$, carrier gas, $\mathrm{N}_{2}(1.2 \mathrm{~mL} / \mathrm{min})$. For each sample, $1 \mu \mathrm{L}$ (10\% EO, in purified hexane) was injected for analysis. The relative concentration was calculated using software HP chemstation, which allows assimilating the percentages of the peak areas to the percentages of the various constituents. Retention indices (RI) were determined relatively to the retention time $\left(t_{R}\right)$ of a series of $\mathrm{n}$ alkanes $\left(\mathrm{C}_{9}-\mathrm{C}_{28}\right)$. 


\section{GC/MS analysis}

The EOs were analysed with a Hewlett-Packard 5890 series II apparatus equipped with a 5972 mass selective detector and an apolar HP5 column $(30 \mathrm{~m} \times 0.32 \mathrm{~mm}$ i.d., film thickness of $0.25 \mu \mathrm{m})$. Helium was used as a carrier gas. The mass spectrometer operating conditions were: ionisation voltage, $70 \mathrm{eV}$; ion source, $230^{\circ}$. The GC analysis was carried out as described above (see GC Analysis).

\section{Compound identification}

The identification of the compounds was based on the comparison of their RI (determined relatively to the $t_{R}$ of n-alkanes $\left(C_{9}-C_{28}\right)$ ) and their mass spectra with those of authentic compounds by means of NBS75K.L. and Wiley 275 databases, as well as with literature data [41].

\section{Antibacterial testing Bacterial strains}

In this study, three clinical bacterial isolates (H. influen$z a e, H$. parainfluenzae, and K. pneumonia) were used, as well as three ATCC bacteria: P. aeruginosa (ATTC 9027), $S$. aureus (ATCC 6538), and E. coli (ATCC 8739). The Microbiology and Immunology Laboratory (EPS Farhat Hachad, Sousse, Tunisia) generously contributed the clinical strains, whereas the ATCC strains were obtained from the culture collection of the Laboratory of Transmissible Diseases and Biologically Active Substances, Faculty of Pharmacy, Monastir, Tunisia.

\section{Kirby Bauer paper method}

Using bacterial inoculums of $0.5 \mathrm{McF}$ arland and Mueller Hinton $(\mathrm{MH})$ enriched with $5 \%$ sheep blood, the antibacterial activity of several EOs was assessed using a paper-disc agar diffusion method. The $\mathrm{MH}$ medium for $P$. aeruginosa, E. coli, and $S$. aureus, on the other hand, was not enriched. Briefly, $10 \mu \mathrm{L}$ of each EO was impregnated into absorbent discs (Whatman disc $\mathrm{N}^{\circ} 3,6 \mathrm{~mm}$ diameter) and then deposited on the surface of infected plates $(90 \mathrm{~mm})$. Gentamicine ${ }^{\circledR}(10 \mathrm{~g} /$ disc $)$ positive control discs were included in each plate. The inhibition zone diameter (izd) was measured and represented in $\mathrm{mm}$ after $24 \mathrm{~h}$ of incubation at $37^{\circ} \mathrm{C}$.

The results were interpreted as follows: i) not sensitive or no inhibitory effect (-) for izd less than $8 \mathrm{~mm}$; ii) sensitive $(+)$ or mild inhibitory effect for izd between 8 and $14 \mathrm{~mm}$; iii) very sensitive or moderate inhibitory effect $(++)$ for izd between 14 and $20 \mathrm{~mm}$; iv) extremely sensitive or strong inhibitory effect $(+++)$ for izd greater than $20 \mathrm{~mm}[42,43]$. All of the tests were carried out in triplicate, and the results were expressed as mean \pm standard errors of mean.

\section{Determination of MIC and MBC}

The minimum inhibitory concentration (MIC) was determined using the micro-well dilution method according to the National Committee for Clinical Laboratory Standards [44]. An overnight incubated culture $\left(37^{\circ} \mathrm{C}\right)$ of each tested bacterial strain was prepared by adjusting the turbidity of each bacterial culture to reach an optical density of $0.5 \mathrm{McF}$ arland standards. One hundred microliters from each EO diluted in DMSO (10\%), initially prepared at a concentration of $931 \mathrm{mg} / \mathrm{mL}$, were added into the third well, followed by two-fold serial dilutions in $\mathrm{MH}$ broth medium until the $12^{\text {th }}$ well. Subsequently, $80 \mu \mathrm{L}$ of $\mathrm{MH}, 10 \mu \mathrm{L}$ of the inoculum, and $10 \mu \mathrm{L}$ of $0.02 \%$ resazurin solution were added into each well. The skipped first and the second wells were reserved for negative and positive controls, respectively. Negative control well contained bacteria in the MH broth medium whereas, positive control well contained bacteria in $\mathrm{MH}$ broth medium and $10 \mu \mathrm{g} / \mathrm{mL}$ of Gentamicin ${ }^{\circledR}$ antibiotics.

After incubation for $24 \mathrm{~h}$ at $37^{\circ} \mathrm{C}$, the bacterial growth was characterized by color change from blue to pink. The MIC was defined as the lowest concentration that completely inhibits visible cell growth after incubation at $37{ }^{\circ} \mathrm{C}$ (blue colored well) for $24 \mathrm{~h}$. To determine the minimum bactericidal concentration (MBC), $10 \mu \mathrm{L}$ of each culture medium with no visible growth were removed and inoculated in $\mathrm{MH}$ plates. After incubation for $18-24 \mathrm{~h}$ at $37^{\circ} \mathrm{C}$, the number of surviving organisms was determined. MBC was defined as the lowest concentration at which $99.9 \%$ of the bacteria culture were killed [7]. As for all analyses, the experiments were performed in triplicate.

\section{Statistical analysis}

We carried out the analysis of variance (ANOVA test) to compare: i) the EO yields among different Eucalyptus species; ii) the quantitative content of chemical components among different Eucalyptus species; iii) izd values obtained during the antibacterial analysis among different EOs and among the used bacterial strains. The significance of the difference between means was determined at $p<0.05$ using Duncan's multiple range test. To evaluate whether the identified EO constituents are a reflection of the chemical and biological activities, the detected 21 chemical compounds in the EO samples (with contents $\geq 2.1 \%$ in at least one species) and all theie izd values were subjected to PCA and HCA analyses using IBM SPSS Statistics for Windows, Version 23.0 (Armonk, NY: IBM Corp). 


\section{Results}

\section{Oil Yields}

The average EO yields for eight Eucalyptus species ranged from $1.4 \% \pm 0.4$ for E. robusta Sm. To $5.1 \pm 0.4 \%$ and $5.2 \pm 0.3 \%$ for E. cladocalyx F. Muell. and E. lesouefii Maiden., respectively (Table 1 ).

The EO yields from three distinct trees revealed that they differed considerably $(p<0.05)$ between species. Four non-overlapping groups of EOs were discovered using the Duncan multiple range test.

\section{Chemical composition of the tested EOs}

The EOs were chromatographically analyzed using GC (RI) and GC (MS), resulting in the identification of 128 compounds (Table 2 Suppl.), accounting for $93.6 \%-97.3 \%$ of the total oil content. These compounds were further divided into 15 classes (Table 2 Suppl.).

The major class was constituted by the monterpenic oxides $(27.4 \%-66.3 \%)$, with 1,8 -cineole having the highest proportion $(28.1 \%-66.3 \%)$ (Table 2$)$. The second major class was constituted by the monterpens hydrocarbons $(4.6 \%-51.2 \%)$, with $\alpha$-pinene and $p$-cymene as prominent constituents $(3.9 \%-38.2 \%$ and $0.4 \%-35.8 \%$, respectively).

The sesquiterpenic alcohols were the third most common class $(2.4 \%-21.6 \%)$, with globulol $(0.0-12.7 \%)$, rosifoliol (trasse $-5.2 \%)$, and spathulenol $(0.0-4.6 \%)$ being the most common. Monoterpenic alcohols $(3.4 \%$ - 23.0\%) are the fourth major class, with $\alpha$-terpineol $(0.2 \%-6.7 \%)$, endo-borneol $(0.3 \%-6.0 \%)$, and transpinocarveol $(2.0 \%-5.3 \%)$ are the most prominent components.

Squiterpene hydrocarbons $(0.4 \%-14.4 \%)$, with aromadendrene as a significant ingredient $(0.1 \%-8.7 \%)$,

Table 1 Classification by means of Duncan's Multiple Range Test of the Average Essential Oil Yields of Eight Eucalyptus Species harvested in June in 2017

\begin{tabular}{ll}
\hline Eucalyptus species & Yield [\%] \\
\hline E.accedens & $2.0 \pm 0.8(\mathrm{a})^{\mathrm{a}}$ \\
E.bosistoana & $3.9 \pm 0.3(\mathrm{c})$ \\
E.cladoalyx & $5.1 \pm 0.4(\mathrm{~d})$ \\
E.lesouefii & $5.2 \pm 0.3(\mathrm{~d})$ \\
E.melliodora & $3.3 \pm 0.7(\mathrm{~b})$ \\
E.punctata & $1.4 \pm 0.4(\mathrm{a})$ \\
E.robusta & $1.7 \pm 0.1(\mathrm{a})$ \\
E.wandoo & $2.0 \pm 0.1(\mathrm{a})$ \\
\hline
\end{tabular}

a Yields with different letters in parentheses differ significantly by Duncan's multiple range test $(p<0.05)$ were the class with the sixth largest content. Monoterpenic ketones $(0.6 \%-12.2 \%)$ were the sixth main class, with cryptone $(0.0-8.4 \%)$ being a prominent element $(0.0-8.4 \%)$.

The aliphatic esters ( $\operatorname{tr}-8.9 \%)$, which include methyl amyl acetate, are the seventh significant class. The monterpene aldehydes $(0.1 \%-3.7 \%)$ were the eighth main class, with citronellal (tr $-3.5 \%$ ) being a prominent element. Minor compounds having a mean proportion of less than $1.1 \%$ made up the rest of the classes.

The monoterpenic oxide 1,8-cineole (66.3\%) represented the highest percentage in EO isolated from $E$. melliodora leaves, as well as a comparatively significant amount of the monterpenic aldehyde trans-pinocarveol and the monoterpenic hydrocarbons $\alpha$-pinene (4\% and $9.2 \%$, respectively). Many additional elements, such as $p$-cymene, $\beta$-pinene, cryptone, and cuminal, were comparatively low.

E. accedens EO had the highest mean percentage of monoterpenic hydrocarbons $\alpha$-pinene (38.2\%), whereas $E$. wandoo $\mathrm{EO}$ had the highest mean percentage of monoterpenic hydrocarbons $p$-cymene and $\gamma$-terpinene (37.7\% and $3.9 \%$, respectively).

The monoterpenic hydrocarbon $\beta$-pinene (10.9\%), the monoterpenic alcohol trepinen-4-ol (3.3\%), and the sesquiterpenic alcohol spathulenol (4.6\%) were found in large amounts in E. lesouefii $\mathrm{EO}$, while $p$-cymene, $\alpha$-pinene, and 1,8-cineole were found in modest amounts $(7.7 \%, 10.8 \%$, and $38 \%$, respectively).

E. pimpiniana $\mathrm{EO}$ had the largest concentrations of the monterpinc ketone cryptone $(8.4 \%)$, monoterpenic alcohol $p$-cymen-8-ol (3.0\%), and monoterpenic aldehyde cuminaldehyde $(2.1 \%)$, as well as a high mean proportion of the monoterpenic hydrocarbons p-cymene and the monoterpene alcohol trans-pinocarveol (28.7\% and $4.2 \%$, respectively).

The monoterpenic alcohols endo-borneol (6.0\%), $\alpha$-terpineol (6.7\%), trans-pinocarveol (5.3\%), sesquiterpenic alcohol rosifoliol (5.2\%), and monoterpenic aldehyde citronellal (3.5\%) were found in the highest concentrations in E. robusta EO, and a relatively high amount of the monoterpenic hydrocarbons $\alpha$-pinene (15.1\%) and $p$-cymene (11.8\%).

In E. cladocalyx EO, the highest mean percentages of sesquiterpenic alcohols globulol (12.7\%), epiglobulol (1.7\%), viridiflorol (2.3\%), sesquiterpenic hydrocarbons aromadendrene $(8.7 \%)$, and ester methyl amyl acetate $(8.9 \%)$ were detected, but $\beta$-pinene, $p$-cymene, and $\alpha$-pinene were very poor.

E. bosistoana EO was relatively rich in 1,8-cineole and $\alpha$-pinene with comparative mean percentages as those observed in E. pimpiniana. 
Table 2 Chemical Composition of the Essential Oils Extracted from Leafs of Eight Eucalyptus Species with content $\geq 1.0 \%$

\begin{tabular}{|c|c|c|c|c|c|c|c|c|c|}
\hline \multirow[t]{2}{*}{ Compound class and Name } & \multirow[t]{2}{*}{$\mathrm{RI}^{\mathrm{a}}$} & \multicolumn{8}{|l|}{ Content [\%] } \\
\hline & & E. accedens & E. bosistoana & E. cladocalyx & E. lesouefii & E. melliodoa & E. robusta & E. punctata & E. wandoo \\
\hline \multicolumn{10}{|l|}{ Monoterpenes hydrocarbons } \\
\hline a-Pinene & 932 & 38.2 & 10.8 & 3.9 & 12.8 & 9.2 & 15.1 & 4.2 & 6.5 \\
\hline Camphene & 952 & 0.1 & 0.1 & $\operatorname{tr}^{b}$ & 0.1 & 0.2 & 1.8 & 0.3 & 0.2 \\
\hline$\beta$-Pinene & 976 & $-c$ & 0.3 & $\operatorname{tr}$ & 10.9 & 0.1 & 0.1 & 5.4 & 0.1 \\
\hline a-Phellandrene & 1005 & 2.2 & 0.2 & $\operatorname{tr}$ & 0.1 & 0.2 & 0.2 & 0.2 & $\operatorname{tr}$ \\
\hline p-Cymene & 1024 & 8.6 & 4.0 & 0.4 & 7.7 & 0.4 & 11.8 & 28.7 & 35.8 \\
\hline$\gamma$-Terpinene & 1057 & 0.1 & 0.1 & 0.1 & 0.3 & $\operatorname{tr}$ & 0.3 & 0.1 & 3.9 \\
\hline \multicolumn{10}{|l|}{ Monoterpene oxides } \\
\hline 1.8-Cineole & 1030 & 28.1 & 52.7 & 39.2 & 38 & 66.3 & 26.5 & 20.7 & 37.7 \\
\hline \multicolumn{10}{|l|}{ Monterpene ketones } \\
\hline Cryptone & 1186 & 0.1 & 0.6 & 0.3 & 0.8 & - & - & 8.4 & 0.2 \\
\hline Verbenone & 1227 & 0.2 & 0.5 & 0.1 & 0.3 & - & 0.6 & 1.5 & 0.2 \\
\hline \multicolumn{10}{|l|}{ Monoterpene aldehydes } \\
\hline Citronellal & 1157 & 0.1 & 0.1 & 0.4 & 1 & 0.1 & 3.5 & 0.2 & $\operatorname{tr}$ \\
\hline Cuminaldehyde & 1239 & $\mathrm{tr}$ & $\operatorname{tr}$ & $\operatorname{tr}$ & 0.1 & $\operatorname{tr}$ & 0.2 & 2.1 & $\operatorname{tr}$ \\
\hline Phellandral & 1274 & - & $\operatorname{tr}$ & - & $\operatorname{tr}$ & $\operatorname{tr}$ & - & 1.1 & $\operatorname{tr}$ \\
\hline \multicolumn{10}{|l|}{ Monterpene alcohols } \\
\hline D-fenchyl alcohol & 1113 & 0.1 & 0.1 & 0.1 & 0.2 & 0.4 & 2.2 & 0.3 & 0.2 \\
\hline trans-Pinocarveol & 1138 & 2.3 & 3.1 & 2 & 3.2 & 4 & 5.3 & 4.2 & 2.2 \\
\hline endo-Borneol & 1162 & 0.5 & 0.9 & 0.3 & 0.4 & 0.7 & 6.0 & 1.1 & 0.4 \\
\hline Borneol & 1171 & $\mathrm{tr}$ & $\operatorname{tr}$ & 0.1 & 1.8 & $\operatorname{tr}$ & 0.4 & 0.3 & $\operatorname{tr}$ \\
\hline Terpinen-4-ol & 1176 & 0.4 & 0.2 & 0.3 & 3.3 & 0.3 & 0.3 & 0.4 & 1.1 \\
\hline$a$-Terpineol & 1191 & 0.5 & 0.9 & 0.2 & 1.2 & 1.6 & 6.7 & 0.5 & 1.2 \\
\hline p-Cymen-8-ol & 1196 & 0.2 & 0.1 & $\operatorname{tr}$ & - & 0.1 & 0.4 & 3.0 & 0.1 \\
\hline Cuminol & 1290 & - & $\operatorname{tr}$ & $\operatorname{tr}$ & 0.1 & $\operatorname{tr}$ & 0.2 & 1.1 & 0.1 \\
\hline \multicolumn{10}{|l|}{ Sesquitepene hydrocarbons } \\
\hline a-Cubebene & 1346 & 0.1 & - & 0.1 & - & 1.7 & - & - & - \\
\hline Aromadendrene & 1438 & 0.2 & 7.3 & 8.7 & 0.4 & 0.6 & 0.2 & 0.1 & 0.1 \\
\hline Alloaromadendrene & 1460 & 0.1 & 1.5 & 1.3 & 0.4 & 0.3 & 0.1 & 0.1 & $\mathrm{tr}$ \\
\hline Ledene & 1492 & $\operatorname{tr}$ & $\operatorname{tr}$ & 1.6 & $\operatorname{tr}$ & - & $\operatorname{tr}$ & 0.1 & $\operatorname{tr}$ \\
\hline \multicolumn{10}{|l|}{ Sesquiterpene alcohols } \\
\hline epiglobulol & 1552 & $\operatorname{tr}$ & 0.9 & 2.3 & 0.1 & 0.1 & 0.3 & 0.1 & $\operatorname{tr}$ \\
\hline Spathulenol & 1577 & 2.5 & 4.1 & 0.2 & 4.6 & 0.5 & 0.2 & 1.6 & - \\
\hline Globulol & 1584 & 2.4 & 2.3 & 12.7 & 0.8 & 1.2 & 1.4 & - & 0.1 \\
\hline Viridiflorol & 1591 & 1 & 0.7 & 2.6 & 0.1 & 0.2 & 0.3 & 0.1 & 0.2 \\
\hline Rosifoliol & 1612 & 0.2 & 0.4 & 1.7 & $\mathrm{tr}$ & $\operatorname{tr}$ & 5.2 & 0.1 & $\mathrm{tr}$ \\
\hline Hinesol & 1642 & 0.6 & 0.1 & 0.1 & - & 0.1 & 0.1 & - & 1.2 \\
\hline$\beta$-Eudesmol & 1645 & 0.7 & 0.2 & 0.5 & 1.1 & - & 0.1 & $\operatorname{tr}$ & 0.3 \\
\hline \multicolumn{10}{|l|}{ Sesquiterpene oxide } \\
\hline Caryophyllene oxide & 1583 & - & - & - & - & - & - & 1.5 & - \\
\hline \multicolumn{10}{|l|}{ Aliphatic esters } \\
\hline Methyl amyl acetate & 900 & $\operatorname{tr}$ & $\operatorname{tr}$ & 8.9 & $\operatorname{tr}$ & $\operatorname{tr}$ & $\operatorname{tr}$ & $\operatorname{tr}$ & $\operatorname{tr}$ \\
\hline
\end{tabular}

${ }^{\mathrm{a}} \mathrm{Rl}$ : Retention index determined on HP5 cap. Column. ${ }^{\mathrm{b}} \mathrm{tr}$ : Trace $(<0.1){ }^{\mathrm{c}}{ }^{\mathrm{N}}$ Not detected

Principal Component (PCA) and Hierarchical Cluster (HCA) analyses

To evaluate whether the identified EO components may be useful in reflecting the chemotaxonomic relationships of the eight Eucalyptus species, 21 chemical compounds with a yield greater or equal to $2.1 \%$ in at least one species (Table 3) were selected for the PCA (Fig. 1) and the HCA analyses (Fig. 2). The concentrations of these 
Table 3 Content [\%] of the 20 Compounds selected for the Principal Component and the Hierarchical Cluster Analyses in the essential Oils Extracted from the Leafs of eight Eucalyptus species

\begin{tabular}{|c|c|c|c|c|c|c|c|c|c|}
\hline \multirow[t]{2}{*}{ Compounds } & \multirow[t]{2}{*}{ Abbreviation } & \multicolumn{8}{|l|}{ Content[\%] } \\
\hline & & E. accedens & E. bosistoana & E. cladocalyx & E. lesouefii & E. melliodoa & E. punctata & E. robusta & E. wandoo \\
\hline a-Pinene & a-pin & $38.2 \pm 13.7$ & $10.8 \pm 4.5$ & $3.9 \pm 0.8$ & $12.8 \pm 0.2$ & $9.2 \pm 0.8$ & $4.2 \pm 2.4$ & $15.1 \pm 2.0$ & $6.5 \pm 0.4$ \\
\hline$B$-pinene & B-pin & - & $0.3 \pm 0.2$ & $\mathrm{tr}$ & $10.9 \pm \mathrm{tr}$ & $0.1 \pm \operatorname{tr}$ & $5.4 \pm 2.4$ & $0.1 \pm \mathrm{tr}$ & $0.1 \pm \operatorname{tr}$ \\
\hline p-cymene & p-cym & $8.6 \pm 2.9$ & $4.0 \pm 0.6$ & $0.4 \pm 0.1$ & $7.7 \pm \operatorname{tr}$ & $0.4 \pm 0.5$ & $28.7 \pm 5.7$ & $11.8 \pm \mathrm{tr}$ & $35.8 \pm 4.3$ \\
\hline 1,8-cineole & 1,8 -cin & $28.1 \pm 6.1$ & $52.7 \pm 8.6$ & $39.2 \pm 5.0$ & $38.0 \pm 0.6$ & $66.3 \pm 1.0$ & $20.7 \pm 12.2$ & $26.5 \pm 0.3$ & $37.7 \pm 4.9$ \\
\hline y-Terpinene & $\gamma$-ter & $0.1 \pm \operatorname{tr}$ & $0.1 \pm \operatorname{tr}$ & $0.1 \pm \operatorname{tr}$ & $0.3 \pm \operatorname{tr}$ & $\operatorname{tr}$ & $0.1 \pm 0.1$ & $0.3 \pm \operatorname{tr}$ & $3.9 \pm 1.9$ \\
\hline trans-Pinocarveol & tr-pin & $2.3 \pm 0.9$ & $3.1 \pm 0.3$ & $2.0 \pm \operatorname{tr}$ & $3.2 \pm \operatorname{tr}$ & $4.0 \pm \operatorname{tr}$ & $4.2 \pm 1.6$ & $5.3 \pm 0.2$ & $2.2 \pm 0.4$ \\
\hline CItronellal & cit & $0.1 \pm \operatorname{tr}$ & $0.1 \pm \mathrm{tr}$ & $0.4 \pm \operatorname{tr}$ & $1.0 \pm \mathrm{tr}$ & $0.1 \pm \operatorname{tr}$ & $0.2 \pm \operatorname{tr}$ & $3.5 \pm 0.1$ & $\operatorname{tr}$ \\
\hline endo-Borneol & enb & $0.5 \pm 0.2$ & $0.9 \pm 0.1$ & $0.3 \pm \operatorname{tr}$ & $0.4 \pm \operatorname{tr}$ & $0.7 \pm \operatorname{tr}$ & $1.1 \pm 0.4$ & $6.0 \pm 0.3$ & $0.4 \pm 0.1$ \\
\hline Terpinen-4-ol & Ter-4-ol & $0.4 \pm 0.1$ & $0.2 \pm \operatorname{tr}$ & $0.3 \pm \operatorname{tr}$ & $3.3 \pm \operatorname{tr}$ & $0.3 \pm \operatorname{tr}$ & $0.4 \pm 0.2$ & $0.3 \pm 0.4$ & $1.1 \pm 0.4$ \\
\hline Cryptone & cry & $0.1 \pm 0.1$ & $0.6 \pm 0.1$ & $0.3 \pm \operatorname{tr}$ & $0.8 \pm \operatorname{tr}$ & $-b$ & $8.4 \pm 1.6$ & - & $0.2 \pm \operatorname{tr}$ \\
\hline a-Terpineol & a-ter & $0.5 \pm \operatorname{tr}$ & $0.9 \pm 0.1$ & $0.2 \pm 0.2$ & $1.2 \pm \operatorname{tr}$ & $1.6 \pm \operatorname{tr}$ & $0.5 \pm 0.2$ & $6.7 \pm 0.3$ & $1.2 \pm 0.3$ \\
\hline p-Cymen-8-ol & p-cy-8-ol & $0.2 \pm \operatorname{tr}$ & $0.1 \pm \operatorname{tr}$ & $\operatorname{tr}$ & - & $0.1 \pm \operatorname{tr}$ & $3.0 \pm 1.2$ & $0.4 \pm \operatorname{tr}$ & $0.1 \pm \operatorname{tr}$ \\
\hline Cuminaldehyde & cum & $\operatorname{tr}$ & $\operatorname{tr}$ & $\operatorname{tr}$ & $0.1 \pm \operatorname{tr}$ & $\operatorname{tr}$ & $2.1 \pm 0.6$ & $0.2 \pm 0.2$ & $\operatorname{tr}$ \\
\hline Aromadendrene & aro & $0.2 \pm 0.2$ & $7.3 \pm 3.7$ & $8.7 \pm 0.7$ & $0.4 \pm \operatorname{tr}$ & $0.6 \pm 0.2$ & $0.1 \pm 0.1$ & $0.2 \pm 0.3$ & $0.1 \pm \operatorname{tr}$ \\
\hline Epiglobulol & epi & $\operatorname{tr}$ & $0.9 \pm 2.3$ & $2.3 \pm 0.5$ & $0.1 \pm \operatorname{tr}$ & $0.1 \pm \operatorname{tr}$ & $0.1 \pm \operatorname{tr}$ & $0.3 \pm \operatorname{tr}$ & $\operatorname{tr}$ \\
\hline Spathulenol & spa & $2.5 \pm 3.2$ & $4.1 \pm 5.1$ & $0.2 \pm \operatorname{tr}$ & $4.6 \pm 0.2$ & $0.5 \pm 0.1$ & $1.6 \pm 0.4$ & $0.2 \pm 0.3$ & - \\
\hline Globulol & glo & $2.4 \pm 0.3$ & $2.3 \pm 0.8$ & $12.7 \pm 2.9$ & $0.8 \pm \operatorname{tr}$ & $1.2 \pm 0.4$ & - & $1.4 \pm 0.1$ & $0.1 \pm \operatorname{tr}$ \\
\hline Viridiflorol & vir & $1.0 \pm 0.2$ & $0.7 \pm 0.1$ & $2.6 \pm 0.6$ & $0.1 \pm \operatorname{tr}$ & $0.2 \pm \operatorname{tr}$ & $0.1 \pm \operatorname{tr}$ & $0.3 \pm \operatorname{tr}$ & $0.2 \pm \operatorname{tr}$ \\
\hline Rosifoliol & ros & $0.2 \pm 0.1$ & $0.4 \pm 0.4$ & $1.7 \pm 0.4$ & $\operatorname{tr}$ & $\operatorname{tr}$ & $0.1 \pm 0.1$ & $5.2 \pm 0.5$ & $\operatorname{tr}$ \\
\hline Methyl amyl acetate & maa & $\operatorname{tr}$ & $\operatorname{tr}^{\mathrm{a}}$ & $8.9 \pm 1.5$ & $\operatorname{tr}$ & $\operatorname{tr}$ & $\operatorname{tr}$ & $\operatorname{tr}$ & $\operatorname{tr}$ \\
\hline
\end{tabular}

${ }^{a}$ tr: Trace $(<0.1 \%){ }^{b-}$ : Not detected

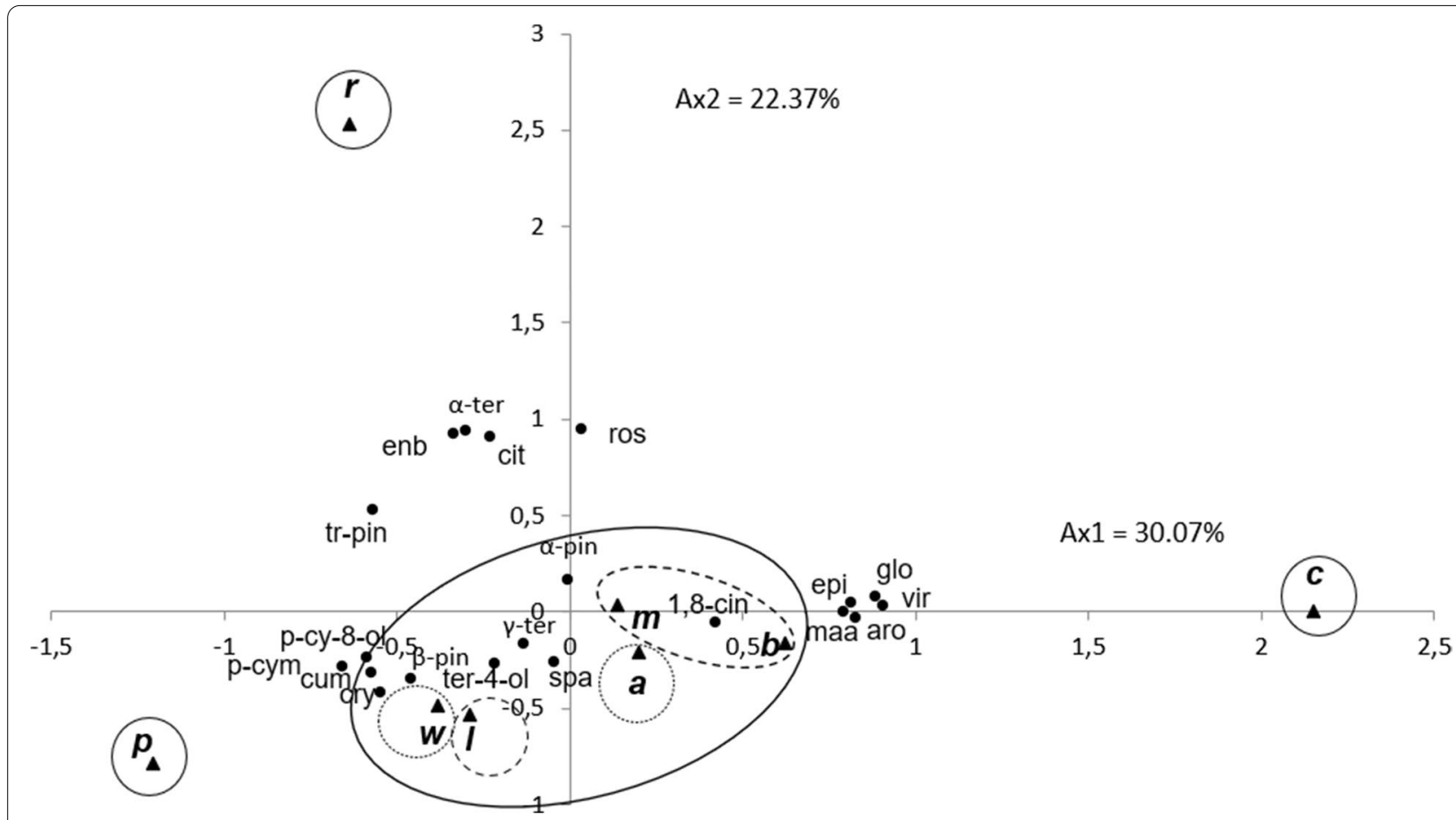

Fig. 1 PCA of twenty components for the leaf essential oils of eight Tunisian Eucalyptus species. For the abbreviation of the Eucalyptus species a: E. accedens; b: E. bosistoana; c: E. cladocalyx; I: E. lesouefeii; m: E. melliodora; p: E. punctata; r: E. robusta; W: E. wandoo 


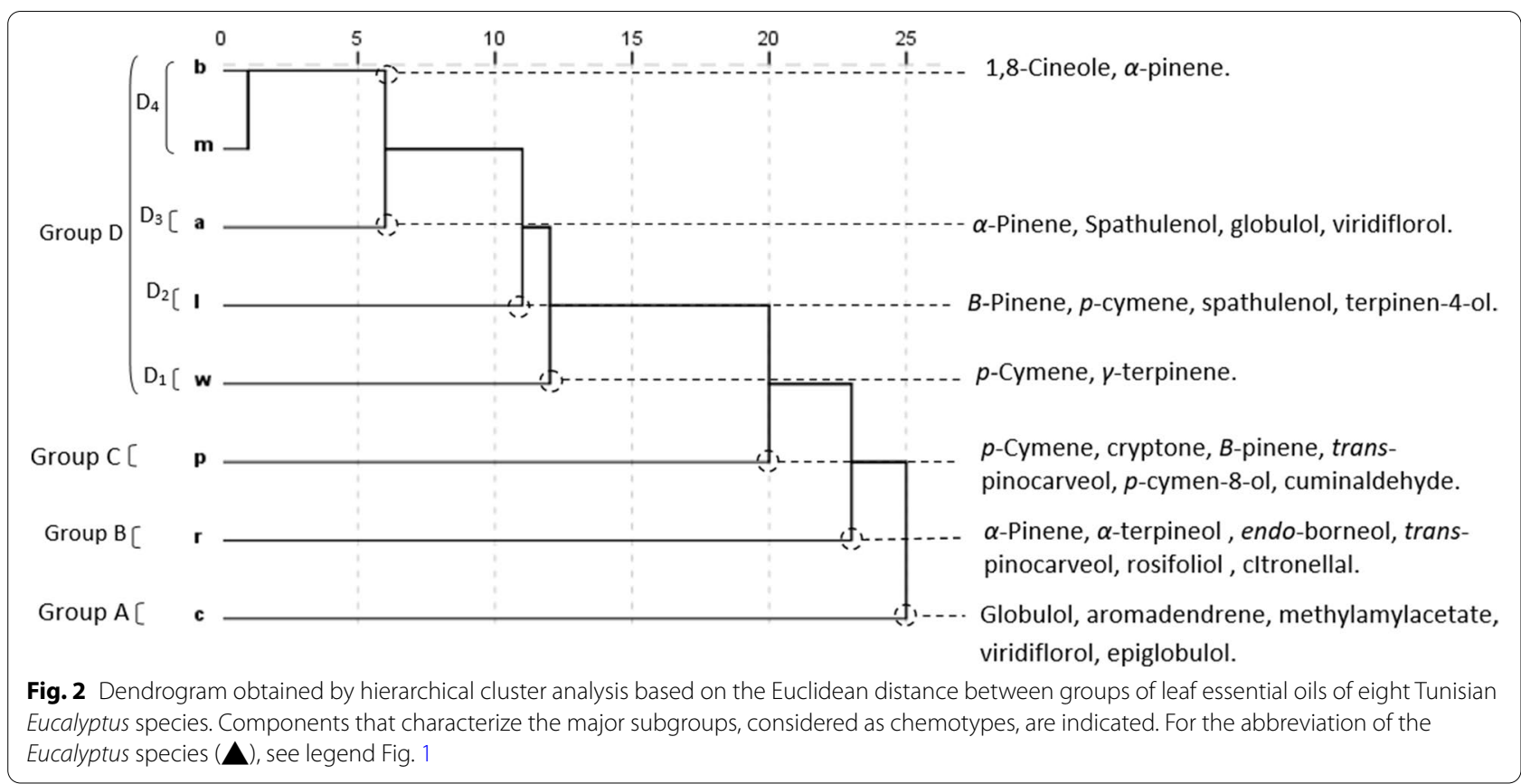

chemical components differed significantly between species $(p<0.05)$.The HCA analysis identified four groups (A, B, C and D), identified by their EO chemotypes with a dissimilarity of greater than $15 \%$. Group D was further divided into four subgroups $\left(\mathrm{D}_{1}-\mathrm{D}_{4}\right)$ with a dissimilarity of greater than $5 \%$. The PCA horizontal axis (axis 1 ) explained $30.07 \%$ of the total variance due to the increasing level of the mean percentage of compounds in group $\mathrm{A}$ and $\mathrm{C}$ species. The variation along the PCA vertical axis (axis 2) (22.37\%) was mainly due to the increase in the mean percentage of compounds in group $B$ and their decreasing level in group $C$ and subgroups $D_{1}$ and $D_{2}$, which stand out in both HCA and PCA analyses, forming separate groups and subgroups. Since components of the EOs within the same group were significantly correlated and tend to vary in the same way, we considered each group as a chemotype. Group A is constituted by E. cladocalyx, for which the EO content is distinguished from other groups by the highest percentages of sesquiterpenic alcohols globulol $(12.7 \pm 2.9 \%)$, epiglobulol $(2.3 \pm 0.5 \%)$, viridiflorol $(2.6 \pm 0.6 \%)$, the sesquiterpenic hydrocarbons aromadendrene $(8.7 \pm 0.7 \%)$ and the ester methyl amyl acetate $(8.9 \pm 1.5 \%)$, but by the absence of the monoterpenic alcohol $p$-cymen-8-ol, monoterpenic hydrocarbons $p$-cymene and the aldehyde cuminal. On the other hand, E. robusta, constituting Group B, was positively correlated with axis 2 and stood out, forming a separate group in both the HCA and PCA analyses. It was characterized by the highest content in the monoterpenic alcohols trans-pinocarveol (5.3 $\pm 0.2 \%)$, endo-borneol $(6.0 \pm 0.3 \%)$, $\alpha$-terpineol (6.7 $\pm 0.3 \%)$, aldehyde citronellal (3.5 $\pm 0.1 \%)$, and the sesquiterpenic alcohol rosifoliol (5.2 $\pm 0.5 \%)$. This separation was enhanced further by its poverty in cryptone, $\beta$-pinene, and terpinen-4-ol. Group $C$, constituted by E. pimpiniana, was negatively correlated with axis 1 . The EO of E. pimpinianais is characterized by its highest content of cryptone $(8.4 \pm 1.6 \%), p$-cymen-8-ol $(3.0 \pm 1.2 \%)$, and cumianldehyde $(2.1 \pm 0.6 \%)$. It was also close to $E$. wandoo of the subgroup $\mathrm{D}_{1}$, likely due to its relative richness in $p$-cymene $(28.7 \pm 5.7 \%)$ and to $E$. lesouefii of the subgroup $\mathrm{D}_{2}$ by its richness in $\beta$-pinene $(5.4 \pm 2.4 \%)$. Both E. robusta and E. pimpiniana EOs were negatively correlated with axis 1 , mainly due to their relative poverty in 1,8 -cineole $(26.5 \pm 0.3$ and $20.7 \pm 12.2 \%$, respectively). Sub-group D1, constituted by E. wandoo, is characterized by $p$-cymene $(35.8 \pm 4.3 \%)$ and $\gamma$-terpinene $(3.9 \pm 1.9 \%)$, whereas E. lesouefii, constituting the subgroup D2, is characterized by $\beta$-pinene $(10.9 \pm 0.0 \%)$, spathulenol $(4.6 \pm 0.2 \%)$ and terpine-4-ol $(3.3 \pm 0.0 \%)$. Subgroup D3, constituted by E. accedens, is characterized by $\alpha$-pinene $(38.2 \pm 13.7 \%)$ and a relatively high content of spathulenol, globulol, and viridiflorol. Subgroup $\mathrm{D}_{4}$, formed by E. melliodora and E. bosistoana oils, is characterized by 1,8 -cineole $(66.3 \pm 1.0 \%$ and $52.7 \pm 8.6 \%$, respectively). The separation between the two species was mainly due to the richness of $E$. bosistoana in aromadendrene (7.3 $\pm 3.7 \%$ ), against $0.6 \pm 0.2 \%$ in E. melliodora. The statistical analysis revealed significant variability in the EOs among the Eucalyptus species. The HCA and PCA analyses identified seven groups and subgroups, 
yet 19 major chemical components were identified; each group constituted a chemotype.

\section{Antibacterial testing}

The EOs were tested for their putative antibacterial activity against six bacterial strains (Table 4). The results showed that, with the exception of Gram negative $P$. aeruginosa, the majority of these bacterial strains were sensitive to the tested EOs. The Gram negative $E$. coli was sensitive to EOs extracted from E. robusta, $E$. melliodora, and E. wandoo, but it was resistant to EO extracted from E. punctata. Moreover, the EO extracted from E. melliodora possessed the best activity against the Gram negative $K$. pneumoniae, followed by those extracted from E. bosistoana and E. robusta. In order to evaluate the relationship between the EOs extracted from the eight Eucalyptus species and their antibacterial activities, all the mean values of izd were subjected to PCA and HCA analyses. Antibacterial activities of the tested EOs showed a significant difference between Eucalyptus species and bacterial strains $(\mathrm{p}<0.05)$. The PCA horizontal axis (axis 1) explained $46.55 \%$ of the total variance, while the vertical axis (axis 2) explained a further $18.4 \%$ (Fig. 3). The HCA analysis identified two EO groups ( $\mathrm{A}^{\prime}$ and $\mathrm{B}^{\prime}$ ) distinguished by antibacterial activity and a dissimilarity greater than or equal to 20 (Fig. 4). With a dissimilarity of $>5$, group A was further subdivided into two subgroups ( $A^{\prime} 1$ and $A^{\prime} 2$ ), whereas group $B$ was further subdivided into three subgroups (B'1, B'2, and B'3). Axis 1 divides group A from group B, while axis 2 divides group $A$ into two subgroups and group $B$ into three subgroups. Group A', constituted by E. accedens, E. punctata and E. lesouefii, forms a deep dichotomy in the HCA analysis and a clearly separated group in the PCA analysis. These species were characterized by their lowest activity against $K$. pneumoniae and E. coli $(6.0 \pm 0.0$ $\mathrm{mm} \leq \mathrm{izd} \leq 12.3 \pm 3.8 \mathrm{~mm}$ ). E. lesouefii of the subgroup A'1 showed the highest activity against the Gram positive S. aureus (13.3 $\pm 1.2 \mathrm{~mm}$, izd). E. accedens and E. punctata, belonging to the subgroup A'2, were more active against $H$. parainfluenzae and $H$. influenzae, respectively. E. robusta, belonging to subgroup B'1, showed similar activity to the reference Gentamicine ${ }^{\circledR}$ against $E$. coli and had moderate activity against $K$. pneumoniae. Subgroup B'2, constituted by E. wandoo oil, was characterized by a mild inhibitory effect against all the tested bacterial strains, except E. coli. Eucalyptus species, belonging to the subgroup B'3, showed relatively moderate activity against $K$. pneumoniae. However, E. melliodora and $E$. cladocalyx showed promising activity against $E$. coli. Altogether, the tested EOs were less active than the Gentamicine ${ }^{\circledR}$. The MIC results showed that the EO, rich in globulol, epiglobulol, methyl amyl acetate and aromadendrene, extracted from E. cladocalyx, showed the lowest MIC value against $H$. influenza (Table 5). The second lowest MIC was shown for E. robusta and E. melliodora against $E$. coli $(14.06 \mu \mathrm{g} / \mathrm{mL}, 25.97 \mu \mathrm{g} / \mathrm{mL}$, respectively). These results were further confirmed by the disc diffusion method. The highest MIC against $S$. aureus and $E$. coli was shown for EOs extracted from $E$. lesouefii and $E$. accedens. The highest MIC against $P$. aeruginosa and $H$. influenzae was shown for EOs extracted from $E$. bosistoana and E. lesouefii $(415.50 \mathrm{mg} / \mathrm{mL})$, whereas the lowest MIC against the same bacterial strain was shown for EO extracted from E. wandoo $(51.94 \mathrm{mg} / \mathrm{mL})$. These findings were in contradiction to the results observed using the disc diffusion method. According to the classification of Schaechter et al. (1999) and Dramane et al. (2010)

Table 4 Diameter of the inhibition of the inhibition of ear infection bacterial growth by individual essential oils and by the antibiotic (Gentamicin)

\begin{tabular}{|c|c|c|c|c|c|c|}
\hline \multirow[t]{3}{*}{ Eucalyptus Species oils } & \multicolumn{6}{|l|}{ Bacterial Strains } \\
\hline & \multicolumn{5}{|l|}{ Gram-negative } & \multirow{2}{*}{$\begin{array}{l}\text { Gram-positive } \\
\text { S.aureus }\end{array}$} \\
\hline & E.coli & H. influenzae & H.parainfluenzae & K. pneumoniae & P.aeruginosa & \\
\hline E. accedens & $12.3 \pm 3.8^{\left.b^{*}\right)}$ & $1 \operatorname{tr} \pm 1.0^{\mathrm{ab}}$ & $12.7 \pm 2.5^{b}$ & $7.0 \pm 1.7^{\mathrm{a}}$ & $6.3 \pm 0.6^{a}$ & $9.3 \pm 0.6^{\mathrm{a}}$ \\
\hline E. bosistoana & $13.7 \pm 1.5^{\left.b c^{* *}\right)}$ & $6.0 \pm \operatorname{tr}^{\mathrm{a}}$ & $7.3 \pm 1.5^{\mathrm{ab}}$ & $16.0 \pm 1.7^{b c d}$ & $6.0 \pm \operatorname{tr}^{\mathrm{a}}$ & $10.7 \pm 4.0^{\mathrm{ab}}$ \\
\hline E. cladocalyx & $15.7 \pm 3.2^{\mathrm{bcd}}$ & $6.0 \pm \mathrm{tr}^{\mathrm{a}}$ & $6.3 \pm 0.6^{a}$ & $15.0 \pm 4.4^{\mathrm{bc}}$ & $6.0 \pm \operatorname{tr}^{\mathrm{a}}$ & $8.0 \pm 2.6^{\mathrm{a}}$ \\
\hline E.lesouefii & $1 \operatorname{tr} \pm 2.0^{\mathrm{ab}}$ & $9.3 \pm 1.2^{a b}$ & $9.3 \pm 2.1^{\mathrm{ab}}$ & $8.7 \pm 1.2^{\mathrm{a}}$ & $8.3 \pm 0.6^{a}$ & $13.3 \pm 1.2^{b}$ \\
\hline E. melliodora & $19.7 \pm 6.7^{\text {de }}$ & $6.3 \pm 0.6^{\mathrm{a}}$ & $7.0 \pm 1.7^{\mathrm{ab}}$ & $19.7 \pm 2.9^{\mathrm{cd}}$ & $6.0 \pm \operatorname{tr}^{\mathrm{a}}$ & $8.3 \pm 2.1^{\mathrm{a}}$ \\
\hline E. punctata & $6.0 \pm \operatorname{tr}^{\mathrm{a}}$ & $11.7 \pm 2.1^{b}$ & $10.7 \pm 3.5^{\mathrm{ab}}$ & $7.0 \pm \mathrm{tr}^{\mathrm{a}}$ & $6.0 \pm \operatorname{tr}^{\mathrm{a}}$ & $9.7 \pm 3.2^{\mathrm{a}}$ \\
\hline E. robusta & $20.7 \pm 1.5^{\text {de }}$ & $1 \operatorname{tr} \pm 1.0^{a b}$ & $1 \operatorname{tr} \pm 2.6^{\mathrm{ab}}$ & $16.0 \pm 4.6^{\mathrm{bcd}}$ & $7.7 \pm 1.5^{\mathrm{a}}$ & $6.3 \pm 0.6^{\mathrm{a}}$ \\
\hline E. wandoo & $18.3 \pm 0.6^{\text {cde }}$ & $9.0 \pm 1.0^{a b}$ & $9.3 \pm 0.6^{\mathrm{ab}}$ & $12.0 \pm 1.7^{\mathrm{ab}}$ & $6.0 \pm \mathrm{tr}^{\mathrm{a}}$ & $9.0 \pm 1.0^{\mathrm{a}}$ \\
\hline Gentamicin & $24.2 \pm 2.3^{e}$ & $31.4 \pm 2.1^{c}$ & $38.6 \pm 2.8^{c}$ & $21.5 \pm 2.4^{d}$ & $26.4 \pm 1.6^{b}$ & $29.9 \pm 1.0^{c}$ \\
\hline
\end{tabular}

${ }^{*}$ Values are means $(\mathrm{mm} \pm \mathrm{MSD})$ of triplicate determination; ${ }^{* *}$ Values with different letters differ significantly by Duncan's multiple range test $(P<0.05)$ 


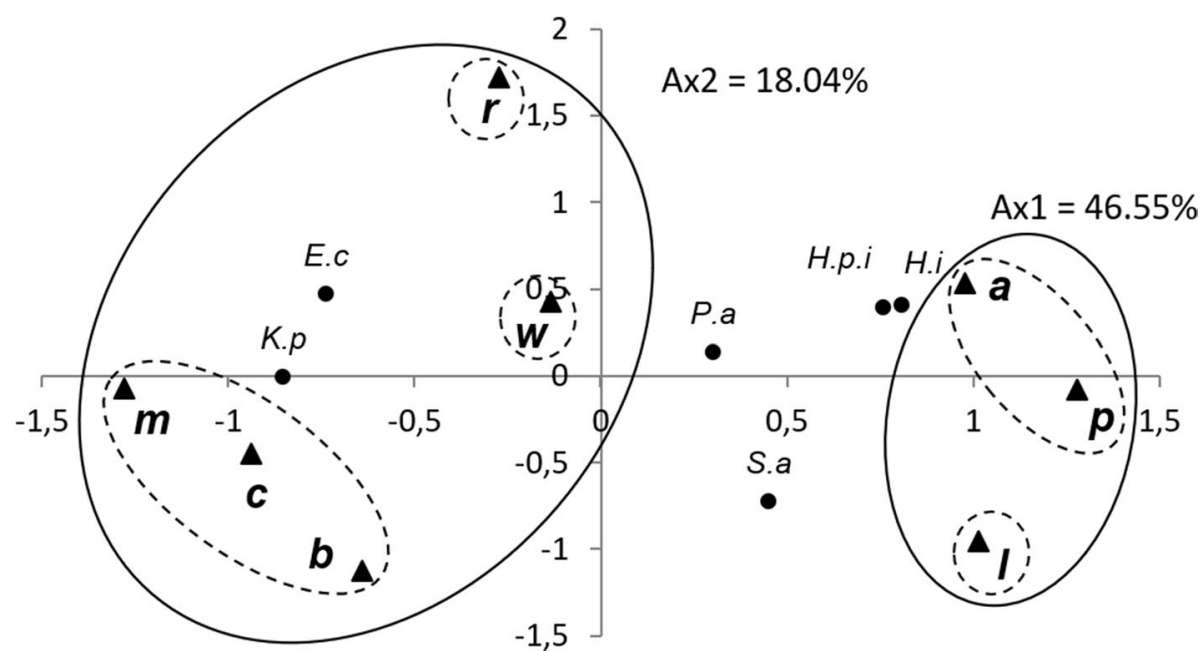

Fig. 3 PCA of the antibacterial activities of leaf essential oils of eight Tunisian Eucalyptus species. For the abbreviation of the Eucalyptus species (A see legend Fig. 1.*) E.c: Echerichia coli; k.p: Klebsiella pneumoniae; P.a: Pseudomonas aeruginosa; S.a: Staphylococcus aureus; H.i: Haemophilus influenzae; H.p.i: Haemophulis parainfluenzae

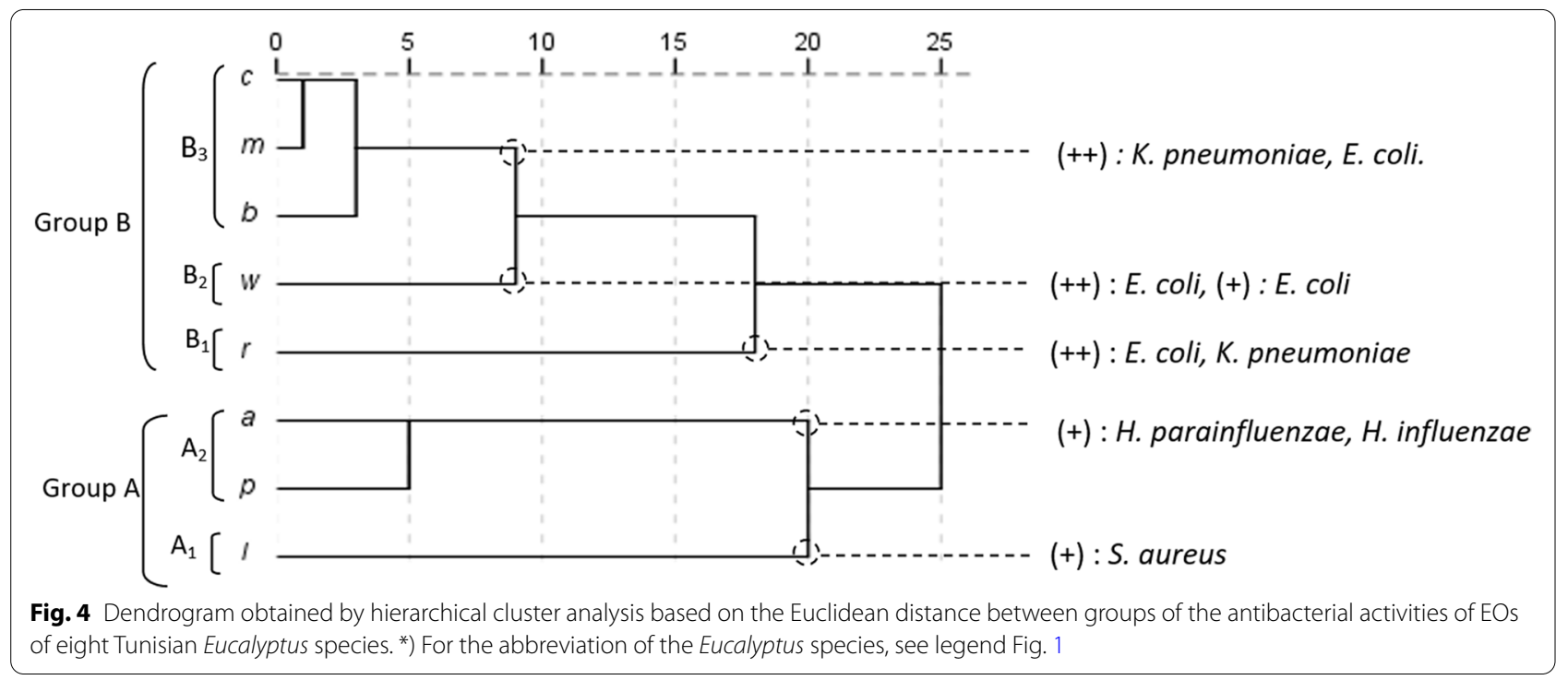

$[45,46]$, all the tested oils were considered Bactericidal against the tested bacterial strains $(\mathrm{MBC} / \mathrm{MIC} \leq 4)$. However, the best bactericidal activity against $P$. aeruginosa, $K$. pneumoniae and $H$. parainfluenzae was observed for EOs extracted from E. punctata and E. bosistoana. Moreover, EOs extracted from E. lesouefii, E. accedens and $E$. melliodora showed promising antibacterial activity against $S$. aureus, whereas EO extracted from E. cladocalyx oil showed high antibacterial activity against both $H$. influenzae and $H$. parainfluenzae.

\section{Discussion}

\section{Oil Yields}

The present results showed that E. cladocalyx F. Muell. grown in Mjez elbab arboretum (North East of Tunisia), was much richer in EO than those obtained from Algeria (0.49\%), Morocco (0.30 - 0.80\%) [47-49], and even from another Tunisian location (Zerniza arboretum, region of Sejnene, North West of Tunisia and Sidi Smail arboretum, Region of Monastir) (1.9 $\pm 0.1-3.06 \%)$ [33, 50]. Additionally, E. melliodora leaves were also richer 


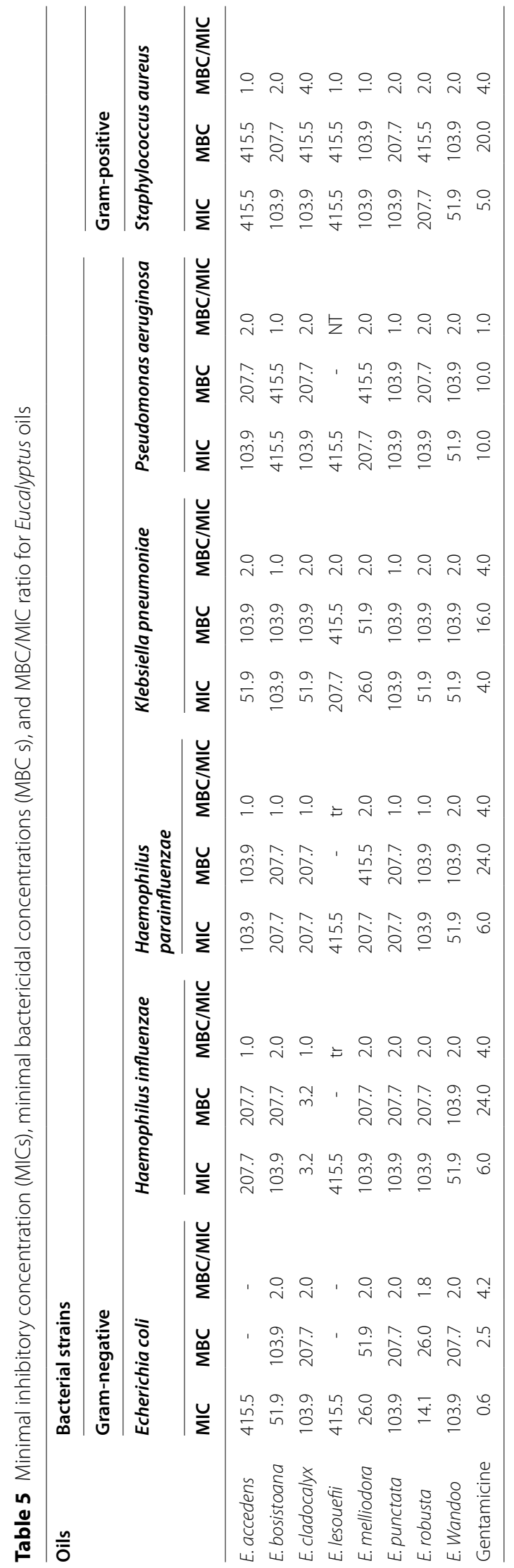


in EOs than those collected from Morocco (1.68\%) [51] and Australia (0.08\%) [52]. However, the Iranian provenance demonstrated similar results with the mean EO yield varying from 2.6 to $3.9 \%$ [53]. Compared with the results obtained by other studies, Tunisian plantation of E. robusta was much richer in EOs than those from Congo (0.13\%) [54], Australia (as tr) [55], Brazil $(0.2-0.34 \%)$ [56, 57], China (0.17\%) [58], and Algeria (0.6\%) [59]. Moreover, the EO yield of E. punctata leaves $(1.4 \pm 0.4 \%)$ showed similar yields as those reported in Australia, Morroco, and Algeria (1.3 \pm 0.6 - 1.57\%) [47, $51,60]$, whereas those from Uruguay provenance showed less EO yield $(0.33 \%)$ [61]. Our findings also revealed that the leaves of $E$. accedens have a higher EO yield than those from Australian plantations (0.9\%) [62]. In addition, E. bosistoana from Tunisia was much richer in EOs $(3.9 \pm 0.3 \%)$ than those obtained from Morocco, Algeria and Portugal $(0.6-1.8 \%)$ [51, 63, 64]. These variations could be linked to the environmental influence on Eucalyptus EO biosynthesis [65-67]. It is worth noting that the EO yields of $E$. Wandoo and $E$. lesouefii have not been studied previously.

\section{Chemical composition of the tested essential oils}

The chemotaxonomic variation shown in the results could be attributed to exogenous factors such as precipitation, temperature, light, soil type, altitude light etc., and to endogenous ones, related mainly to the anatomical, physiological and genetic characteristics of the plant, controlling the EO biosynthesis. Furthermore, the environment may influence the DNA of the aromatic plants, resulting in different genotype [68]. It was reported that the chemical composition of both E. camaldulensis and E. loxophleba EOs was dependent on their physiological stage, which was dependent on genetic factors and on external factors such as soil moisture conditions [67, 69]. Moreover, the correlation between the EOs' chemical composition and the genetic diversity of many aromatic plant species has been demonstrated by a number of researchers who point out the chemotype / genotype association [70,71].

E. bosistoana $\mathrm{EO}$ has similar major compounds to those obtained by Zrira et al.(1992) [51] with a small difference in their mean percentages. However, the studies of Faria et al. (2011) [64] and Bouzabata et al. (2014) [63] noted the presence of other major components such as $\alpha$-terpineol (6.9\%), limonene (4.5\%), $p$-cymene $(32.0 \%-39.5 \%)$, cryptone $(11.5 \%-15.6 \%)$, and $\alpha$-pinene (11.6\% - 12.1\%). E. punctata and E. melliodora from Morocco and Algeria were much richer in 1,8-cineole (44.0\% and $58.2 \%$, respectively) and in $\alpha$-pinene (19.6\% and $7.7 \%$, respectively) $[47,51]$. Our findings on their major EOs components agree with the results obtained by Southwell (1973) [60] and Bignell et al. (1997d) [55], but our results disagree with those obtained by Filomeno et al. (2017) [56], which demonstrated the presence of a relatively high content in 1,8-cineole (55.6\%), $\alpha$-pinene (27.2\%), $\alpha$-phellandrene (6.8\%), and a low mean percentage of $p$-cymene $(3.0 \%)$ in the Brazialian E. punctata EO [72]. E. wandoo from Algeria was much poorer in 1,8 -cineole and $p$-cymene (14.9\% and 9.0\%, respectively), but it was distinguished by its high content of benzaldehyde (32.3\%) [47]. The latter compound was not detected in our investigation. E. robusta from Algeria and Indonesia $[59,73]$ were characterized by a higher content of 1,8 -cineole $(50.0 \%$ and $55.8 \%$, respectively) and $\alpha$-pinene (22.2\% and $37.05 \%$, respectively) than that obtained from Tunisia, whereas a similar percentage of 1,8-cineole was observed in the China provenance [58] with a higher content of $\alpha$-pinene (30.18\%). Moreover, different main compounds such as myrtenal, pinocarvone, isobicyclogermacral and $\alpha$-phellandrene were detected in those from Australia, Congo and Brazil [54-56]. The E. accedens EO from Australia was much richer in 1,8-cineole (71.5\%), trans-pinocarveol (15.8\%), and aromadendrene $(7.3 \%)$ than the one obtained in our study, but the Tunisian E. accedens EO was richer in $\alpha$-pinene $(38.2 \pm 13.7 \%)$ than the Australian one (9\%) [62]. Different main compounds were detected in E. cladoca$l y x$ from Zerniza arboretum (North of Tunisia), such as $\alpha$-terpineol $(18.0 \pm 4.5 \%)$ and boroneol $(24.8 \pm 4.1 \%)$ [74], but we noted a relatively high mean percentage of methyl amyl acetae $(8.9 \pm 1.5 \%)$ in samples from Mjez elbeb arboretum and its complete absence in the same species from Zerniza arboretum, which was relatively poor in 1,8 -cineole $(3.0 \pm 0.0 \%)$, globulol $(0.3 \pm 0.6 \%)$ and aromadendrene (0.1\%).

The variation in the chemical composition of the EOs could be attributed to environmental factors that affect the biosynthesis of the EOs' compounds in both quantity and quality [75]. To the best of our knowledge, the chemical composition of E. lesouefi $\mathrm{EO}$ has not been studied previously.

\section{Antibacterial testing}

Altogether, the antibacterial activity of the EOs displayed considerable variation among the different Eucalyptus species oils, but is still much lower than that of the standard antibiotic Gentamicine ${ }^{\circledR}$. This variability could be attributed to the chemical composition of the leaf oils [76].

The EO extracted from E. robusta, rich in the monoterpene aldehyde citronellal, the monterpene alcohols endo-borneol, $\alpha$-terpineol and the sesquiterpene alcohol rosifoliol, showed the highest activity against $E$. coli and a moderate inhibitory effect 
against $K$. pneumoniae. The EO extracted from $E$. punctata, characterized by the highest amount of the ketone cryptone, the monterpene aldehyde cuminal, the monoterpene alcohol $p$-cymen-8-ol and monoterpene hydrocarbons p-cymene $(28.7 \pm 5.7 \%)$, showed the lowest inhibition effect against E. coli and K. pneumoniae, but had the highest activity against $H$. influenzae. The main activity against $E$. coli is likely attributed to the higher content of the components characterizing E. robusta EO (monoterpene aldehyde citronellal, the monterpene alcohols endo-borneol, $\alpha$-terpineol and the sesquiterpene alcohol rosifoliol), whereas $H$. influenzae was more sensible to EOs rich in cryptone, cuminal, p-cymen-8-ol and p-cymene. It was reported by Griffin et al. (1999), that compounds of smaller volume with high hydrogen-bonding capacity interact significantly with water and tend to be active against the Gram negative E. coli [77]. It was also reported by the same author that the aldehyde citronellal has low water solubility and was inactive against the same strain. Therefore, we could deduce that the monoterpene alcohols, endoborneol, $\alpha$-terpineol, could be the main compounds responsible for the activity against $E$. coli. E. melliodora oil, characterized by the highest mean percentage of 1,8-cineole, produced the highest antibacterial activity against $K$. pneumoniae and a medium inhibitory effect against $E$. coli. In E. bosistoana EO, this activity has decreased, as evidenced by a lower mean percentage of 1,8-cineole and a higher content of spathulenol. Altogether, these findings suggest that the main activity against these strains may be attributed to the richness of the EOs in 1,8-cineole, but the decrease in activity could be due to the presence of a high content in spathulenol. This finding was supported by previous studies [78, 79], which reported that 1,8-cineole had strong antibacterial activity against many important pathogens, such as E. coli, S. aureus, and B. Subtilis. $E$. cladocalyx was placed in the same subgroup as the previous Eucalyptus species in the antibacterial HCA and PCA analyses, but it was classified into another subgroup within the chemical HCA and PCA analyses, suggesting that other chemical components characterizing the oil could be involved in the total activity, such as globulol and methyl amyl acetate. Furthermore, the synergetic effect with 1,8 -cineole could produce a similar effect observed with oils rich in 1,8-cineole and poor in spathulenol. Hendry et al. (2009) and Miguel et al. (2018) [80, 81], reported that 1,8-cineole combined with other terpenes such as camphene, $\alpha$-pinene, globulol and limonene was, by synergetic effect, more efficient against $S$. aureus, methicillin-resistant $S$. aureus (MRSA), E. coli and P. aeruginosa.
E. lesouefii EO, characterized by its high levels of $\beta$-pinene, terpinen-4-ol and sapthulenol, exhibited the best inhibition activity against both $S$. aureus and $P$. aeruginosa. However, it remains less important than other EOs, particularly against $K$. pneumoniae and $E$. coli. Comparing the variability of $S$. aureus sensivity to the oils having less concentration of the previous first three compounds and an equal or superior content of $p$-cymene, trans-pinocarveol, $\alpha$-terpineol and citronellal, we could conclude that by antagonism effect, the latter compounds may be responsible for the decrease in activity. However, the increasing level of EOs' effect on the same strain could be due to a synergetic effect between $\beta$-pinene, terpinen-4-ol, spathulenol and other minor compounds such as aromadendrene and epiglobulol. Hammer et al. (2003) and Inouye et al. (2001) [82, $83]$, reported that the monoterpene alcohol terpinen-4-ol has strong antifungal and antibacterial activity, especially against $S$. aureus. However, many studies have reported that minor compounds may have synergetic or additive [84]. The correlation between the chemical composition and the antibacterial activity of the tested oils also showed that the low activity against $P$. aeruginosa, which was observed with E. lesouefii and E. robusta oils, could be due to a synergetic effect mainly between terpinen4-ol, $\beta$-pinene, citronellal, $\alpha$-terpineol and other compounds such as spathulenol, rosifoliol, endo-borneol, but the presence of high levels of $p$-cymene, 1,8-cineole and the presence of other minor components such as aromadendrene, viridiflorol, globulol may considerably reduce the effect of the EO. E. accedens EO, characterized by the highest mean percentage of $\alpha$-pinene and sharing almost the same mean percentage of $p$-cymene and 1,8-cineole with $E$. robusta EO, was relatively more effective against $H$. parainfluenzae. The EOs extracted from E. melliodora and E. bosistoana, on the other hand, were ineffective against $H$. parainfluenzae and $H$. influenzae due to their high content of 1,8-cineole and low content of $p$-cymene and $\alpha$-pinene. Similarly, E. cladocalyx EO, which has a nearly identical content of 1,8-cineole as E. accedens EO and a very low content of $\alpha$-pinene, $p$-cymene, aromadendrene, globulol, viridiflorol, and methyl amyl acetate, did not show antibacterial activity against the two strains mentioned above.Altogether, $\alpha$-pinene could be the principal compound responsible for the activity against $H$. parainfluenzae, whereas $p$-cymene and $\alpha$-pinene synergically have an effect on the inhibition of growth of the two Haemophilus strains; 1,8-cineole, aromadendrene, globulol, viridiflorol and methyl amyl acetate could exhibit an antagonism effect causing a significant diminution of the EO activity. This result was confirmed by the correlation analysis of the chemical composition and the antibacterial activity of $E$. wandoo $\mathrm{EO}$, showing that the activity 
of the EOs was significantly reduced due to an antagonism effect of 1,8-cineole and other minor compounds, such as aromadendrene, epiglobulol and viridiflorol. The comparative study of our results with those obtained by Sartorelli et al. (2007) [57], showed that the EO of $E$. robusta from Brazil, which was a chemotype of $\alpha$-pinene (73.0\%), limonene (8.3\%) and $\beta$-pinene (6.8\%), exhibited lower inhibition zone diameters $(8.5,6.3 \mathrm{~mm})$ against $E$. coli and $P$. aeruginosa; respectively. However, the EOs from Congo, which were richer in $p$-cymene (27.3\%), myrtenal (12.8\%), and $\beta$-pinene $(6.3 \%)$ and much poorer in 1,8-cineole $(3.5 \%)$ exhibited a higher effect against $S$. aureus $(22,25 \mathrm{~mm}$, izd) and $P$. aeruginosa $(9,16 \mathrm{~mm})$ and a lower activity against $E$. coli $(13,15 \mathrm{~mm}$, izd) [54] than those of the Tunisian E. robusta oil, which was richer in 1,8-cineole, endo-borneol citronellol and rosifolilol. This allowed us to deduce that the latter three components, which were absent in the samples from Congo, might be responsible for the high activity against $E$. coli. The oil of E. cladocalyx from Tunisia (Zerniza arboretum), which was also higher in $p$-cymene $(24.72 .0 \%)$, borneol (24.74.0\%), and $\alpha$-terpineol (18.84.4) than that from Mjez Elbab arboreta, had lower activity against E. coli $(9.00 .0 \mathrm{~mm}$, izd) [38]. However, both of them were inactive against $S$. aureus and $P$. aeruginosa. The difference in activity could be due to the richness of the oils obtained from Mjez Elbab arboretum of 1,8-cineole, globulol, viridiflorol and methyl amyl acetate. It has been reported that most terpenoids have high antimicrobial activity, and that this activity is linked to their hydroxyl group and the presence of delocalised electrons [85].

The MIC results obtained for E. cladocalyx against $H$. influenzae were in contradiction to the results obtained by the diffusion disc method. This difference could be related to the low diffusion ability of the EO, which in itself is highly dependent on water solubility and the ability of active components to diffuse through the agar [77, 81].

In the present study, we used two methods for antibacterial activity: the disc diffusion method and the microbroth dilution method. Each of these methods has its associated advantages and disadvantages. For the disc diffusion method, the interaction between extracts/ bacteria is visually read. However, the inhibition zone could be populated with a minor subpopulation of bacteria, not detected visually; exhibiting increased antibiotic resistance, thus allowing them to grow closer to the disc. Although the disc diffusion test is relatively easy to setup and inexpensive, it does not provide quantitative data. For quantitative data, tests like the microbroth dilution method are available. Therefore, the antibacterial activity procedures depend on the method used as well as the chemical composition of tested compounds [44,
86, 87], as well as the used bacterial strains[87]. Consequently, results obtained by the disc diffusion and broth dilution methods may show a weak positive correlation or even negative correlation for some natural compounds [88].The effect of many factors on the antibacterial activity response, such as water solubility, diffusion index of the natural compound through the agar medium, and the loss of some molecules by vaporisation mainly for essential oils was reported $[77,86]$. It was also known that in the case of Gram negative bacteria, the activity was also dependent on the volume and the polarity of the natural components as well as the polarity of bacteria lipopolysaccharide (LPS) layer [89]. In the present study, a difference in results was shown in the antibacterial activity of some compounds. Among them, the essential oils of $E$. melliodora and E. bosistoana are characterized by their high content of 1,8-cineole, known by its low hydrogenbonding capacity $[77,90]$. Therefore, their antibacterial activity against $K$. pneumoniae using the broth microdilution method, which depends on the interaction of compound molecules in solution, showed high MIC values. Additionally, discordant results were shown for E. robusta, E. melliodora and E. wandoo using both discussed methods against $E$. coli. Although the essential oils of these species had nearly the same inhibition zone diameter as Gentamicine ${ }^{\circledR}$, their MIC values were not the same. Aside from the previously mentioned high content of 1,8-cineole, these three species also had a high content of monoterpene hydrocarbons ( $\alpha$-pinene and $p$-cymene), which are known for their low hydrogenbonding capacity [77]. Altogether, we could confirm that the antibacterial activities by these two methods were not parallel [88]. Indeed, it is more reliable to use the two methods for screening the antimicrobial activity of natural compounds.

Finally, in light of the problems associated with antibiotics, i.e. bacterial resistance, EOs extracted from $E$. bosistoana, E. robusta, and E. melliodora, could be used as an alternative to treat ear infections.

\section{Conclusion}

The chemical PCA and HCA analyses separated the EOs extracted from eight Eucalyptus species into seven groups. Each group constituted a chemotype. On the other hand, PCA and HCA analyses of their antibacterial activity separated them into five subgroups of Eucalyptus species EOs, identified by their levels of antibacterial growth inhibition. E. melliodora and E. bosistoana of the subgroup $\mathrm{D}_{4}$ were the richest species in 1,8-cineole while the highest mean percentage of $\alpha$-pinene and $p$-cymene were detected in E. accedens (Subgroup $\mathrm{D}_{3}$ ) and E. wandoo (subgroup $\mathrm{D}_{1}$ ), respectively. The antibacterial activity of the tested Eucalyptus 
oils varied significantly between species and strains. Compared to the antibiotic Gentamicine ${ }^{\circledR}$, P. aeruginosa, $H$. influenzae, $H$. parainfluenzae, and $S$. aureus were more resistant to all the tested oils. E. robusta and $E$ melliodora oils, belonging to different chemotypes, exhibited the best inhibition zone diameter against $E$. coli and $K$. pneumoniae, respectively. In general, the highest antibacterial activity was not dependent only on a high mean percentage of one major compound such as 1,8 -cineole, but also on the presence of moderate and minor compounds such as citronellal, endo-borneol, $\alpha$-terpineol and rosifoliol. E. melliodora and E. bosistoana oils may have an interesting prospect in therapeutic application of some bacterial strains such as E. coli and K. pneumoniae, responsible for ear infection.

\section{Abbreviations}

GC: Gaz chromatography; GC/MS: Gaz chromatography coupled to the mass spectroscopy; HP: Hewlett-Packard; FID: Flame ionization detector; cap: Capillary; anal: Analytical; i.d.: Internal diamaeter; EOs: Essential oils; MH: Mueller-Hinton; MIC: Minimal inhibition concentration; MBC: Minimum bactericidal concentration; IZD: Inhibition zone diameter; DMSO: Dimethyl sulfoxide; PCA: Principal components analysis; HCA: Hierarchical clusters analysis; Rl: Retention index.

\section{Supplementary Information}

The online version contains supplementary material available at https://doi. org/10.1186/s12906-021-03379-y.

\section{Additional file 1.}

\section{Acknowledgements}

This study was carried out with the support of "Chemical, Pharmacological and Gallenic Development Laboratory, Faculty of Pharmacy of Monastir, Tunisia" and "Laborotary of Separation Sciences, Department of Organic Chemistry, Gent University, Krijgaslaan 281 S4 bis, B-9000 Gent - Belgium"

\section{Authors' contributions}

E.A. performed the Essential oil extraction, the GC/MS analysis, compiled the data and wrote the manuscript; M.S. performed the GC/FID analysis and helped in the antibacterial activity; D. y. helped in the antibacterial activity; K.R. allowed us the use of the GC/MS apparatus and helped in the validation of the analysis method; K.M and K. M.L. collected and identified the plant material; A.N. has checked and corrected the article. All authors have read and agreed to the published version of the manuscript.

\section{Funding}

No external funding was received.

\section{Availability of data and materials}

Data and materials are available from authors on reasonable request.

\section{Declarations}

\section{Ethics approval and consent to participate}

Not applicable. The Eucalyptus is not an endangered plant, and all the plant samples were harvested from the forestry arboreta by Pr. Khouja Mohamed larbi belonging to the forestry department which looks after all the arboreta in Tunisia.

\section{Consent for publication}

Not applicable.

\section{Competing interests}

The authors declare that they have no competing interests.

\section{Author details}

${ }^{1}$ Chemical, Pharmacological and Gallenic Development Laboratory, University of Monastir, Faculty of Pharmacy, Avenue Avicennne, 5000 Monastir, Tunisia. ${ }^{2}$ University of Carthage, The National Research Institute of Rural Engineering, Water and Forestry, INRGREF, Laboratory of Management and Valorization of Forest Resources, BP 10, 2080 Ariana, Tunisia. ${ }^{3}$ Laboratory of Transmissible Diseases and Biological Active Substances LR99ES27, Faculty of Pharmacy, University of Monastir, Monastir, Tunisia. ${ }^{4}$ High Institute of Biotechnology of Sidi Thabet, University of Manouba, Manouba, Tunisia. ${ }^{5}$ Separation Science Group, Department of Organic and Macromolecular Chemistry, Faculty of Sciences, Ghent University, Krijgslaan 281-S4 Bis, B-9000 Ghent, Belgium.

Received: 22 September 2020 Accepted: 15 July 2021

Published online: 12 August 2021

\section{References}

1. Sebei K, Sakouhi F, Herchi W, Khouja M, Boukhchina S. Chemical composition and antibacterial activities of seven Eucalyptus species essential oils leaves. Biol Res. 2015;48(1):7.

2. Bignell CM, Dunlop PJ, Brophy JJ, Fookes CJR. Volatile Leaf Oils of some South-western and Southern Australian Species of the Genus Eucalyptus (Series I). Part XIV. Subgenus Monocalyptus. Flavour Fragr J. 1997;12(3):177-183.

3. Van Hellemont J. Compendium de Phytothérapie. Association Pharmaceutique Belge; 1986. https://books.google.tn/books?id=bSI7xgEACAAJ

4. Pino JA, Marbot R, Quert R, García H. Study of essential oils of Eucalyptus resinifera Smith, E. tereticornis Smith and Corymbia maculata (Hook.) K. D. Hill \& L. A. S. Johnson, grown in Cuba. Flavour Fragr J. 2002;17(1):1-4. doi:https://doi.org/10.1002/ffj.1026

5. Bockstael K, Aerschot A. Antimicrobial resistance in bacteria. Open Med. 2009;4(2):141-55

6. Serwecińska L. Antimicrobials and Antibiotic-Resistant Bacteria: A Risk to the Environment and to Public Health. Water. 2020;12(12):3313.

7. Elaissi A, Rouis Z, Salem NAB, et al. Chemical composition of 8 eucalyptus species' essential oils and the evaluation of their antibacterial, antifungal and antiviral activities. BMC Complement Altern Med. 2012;12(1):81.

8. Horváth G, Ács K. Essential oils in the treatment of respiratory tract diseases highlighting their role in bacterial infections and their anti-inflammatory action: a review: Essential oils in the treatment of respiratory tract diseases. Flavour Fragr J. 2015;30(5):331-41.

9. Brochot A, Guilbot A, Haddioui L, Roques C. Antibacterial, antifungal, and antiviral effects of three essential oil blends. Microbiologyopen. 2017;6(4):e00459.

10. Luís Â, Duarte A, Gominho J, Domingues F, Duarte AP. Chemical composition, antioxidant, antibacterial and anti-quorum sensing activities of Eucalyptus globulus and Eucalyptus radiata essential oils. Ind Crops Prod. 2016;79:274-82.

11. Boonyanugomol W, Kraisriwattana K, Rukseree K, Boonsam K, Narachai P. In vitro synergistic antibacterial activity of the essential oil from Zingiber cassumunar Roxb against extensively drug-resistant Acinetobacter baumannii strains. J Infect Public Health. 2017;10(5):586-92.

12. Jarrar N, Abu-Hijleh A, Adwan K. Antibacterial activity of Rosmarinus officinalis $\mathrm{L}$. alone and in combination with cefuroxime against methicillinresistant Staphylococcus aureus. Asian Pac J Trop Med. 2010;3(2):121-123.

13. Merghni A, Noumi E, Hadded O, et al. Assessment of the antibiofilm and antiquorum sensing activities of Eucalyptus globulus essential oil and its main component 1,8-cineole against methicillin-resistant Staphylococcus aureus strains. Microb Pathog. 2018;118:74-80.

14. Rudramurthy GR, Swamy MK, Sinniah UR, Ghasemzadeh A. Nanoparticles: Alternatives Against Drug-Resistant Pathogenic Microbes. Molecules. 2016;21(7):836.

15. Boukef, M.K. Médecine traditionnelle et pharmacopée, Agence de Coopération Culturelle et Technique, France; 1986.

16. Rusan M, Klug TE, Ovesen T. An overview of the microbiology of acute ear, nose and throat infections requiring hospitalisation. Eur J Clin Microbiol Infect Dis. 2009;28(3):243-51. 
17. Amna Islam MA, Munawerah Fahad AM. Acute Otitis Media: Identification of Causative Pathogens with Antimicrobial Comparative Efficacy. J App Pharm. 2015;7(4):205

18. Nwabuisi C, Ologe FE. Pathogenic agents of chronic suppurative otitis media in Ilorin. Nigeria East Afr Med J. 2002;79(4):202-5.

19. Wang L, Qiao X, Ai L, Zhai J, Wang X. Isolation of antimicrobial resistant bacteria in upper respiratory tract infections of patients. 3 Biotech. 2016;6(2):166

20. Pettigrew MM, Laufer AS, Gent JF, Kong Y, Fennie KP, Metlay JP. Upper Respiratory Tract Microbial Communities, Acute Otitis Media Pathogens, and Antibiotic Use in Healthy and Sick Children. Appl Environ Microbiol. 2012;78(17):6262-70

21. Pang B, Swords WE. Haemophilus parainfluenzae Strain ATCC 33392 Forms Biofilms In Vitro and during Experimental Otitis Media Infections. Infect Immun. 2017;85(9):e01070-e1116.

22. Bruyette DS, Lorenz MD. Otitis externa and otitis media: diagnostic and medical aspects. Semin Vet Med Surg Small Anim. 1993;8(1):3-9.

23. DeAntonio R, Yarzabal J-P, Cruz JP, Schmidt JE, Kleijnen J. Epidemiology of otitis media in children from developing countries: A systematic review. Int J Pediatr Otorhinolaryngol. 2016;85:65-74.

24. Vos T, Barber RM, Bell B, et al. Global, regional, and national incidence, prevalence, and years lived with disability for 301 acute and chronic diseases and injuries in 188 countries, 1990-2013: A systematic analysis for the Global Burden of Disease Study 2013. Int J STD AIDS. 2015;386(9995):743-800.

25. Monasta L, Ronfani L, Marchetti F, et al. Burden of Disease Caused by Otitis Media: Systematic Review and Global Estimates. PLOS ONE. 2012;7(4):e36226.

26. Avnstorp MB, Homøe P, Bjerregaard P, Jensen RG. Chronic suppurative otitis media, middle ear pathology and corresponding hearing loss in a cohort of Greenlandic children. Int J Pediatr Otorhinolaryngol. 2016:83:148-53.

27. World Health Organization. (2018). Addressing the rising prevalence of hearing loss. World Health Organization. https://apps.who.int/iris/handle/ 10665/260336. Licence: CC BY-NC-SA 3.0 IGO

28. Bardaweel S, Hudaib M, Tawaha K. Evaluation of Antibacterial, Antifungal, and Anticancer Activities of Essential Oils from Six Species of Eucalyptus. J Essent Oil Bear PI. 2014;17(6):1165-74.

29. Lin W, Jianbo S, Wanzhong L, et al. Protective effect of eucalyptus oil on pulmonary destruction and inflammation in chronic obstructive pulmonary disease (COPD) in rats. J Med Plants Res. 2017;11(6):129-36.

30. Soying be O, Makhafola T, Mahlobo B, Salahdeen H, Lawal OA, Opoku A. Antiasthma activity of Eucalyptus grandis essential oil and its main constituent: Vasorelaxant effect on aortic smooth muscle isolated from nomotensive rats. J Exp Appl Anim Sci. 2017;2:211.

31. Elaissi A, Chraif I, Bannour F, et al. Contribution to the Qualitative and Quantitative Study of Seven Eucalyptus Species Essential Oil Harvested of Hajeb's Layoun Arboreta (Tunisia). J Essent Oil Bear PI. 2007;10(1):15-25.

32. Elaissi A, Medini $\mathrm{H}$, Marzouki $\mathrm{H}$, et al. Variation in Volatile Leaf Oils of Twelve Eucalyptus Species Harvested from Hajeb Layoun Arboreta (Tunisia). Chem Biodivers. 2010;7(3):705-16.

33. Elaissi A, Marzouki H, Medini H, et al. Variation in Volatile Leaf Oils of 13 Eucalyptus Species Harvested from Souinet Arboreta (Tunisia). Chem Biodivers. 2010;7(4):909-21.

34. Elaissi A, Medini H, Larbi Khouja M, et al. Variation in Volatile Leaf Oils of Eleven Eucalyptus Species Harvested from Korbous Arboreta (Tunisia). Chem Biodivers. 2010;7(7):1841-54.

35. Elaissi A, Medini H, Khouja ML, et al. Variation in Volatile Leaf Oils of Five Eucalyptus Species Harvested from Jbel Abderrahman Arboreta (Tunisia). Chem Biodivers. 2011:8(2):352-61.

36. Elaissi A, Medini H, Simmonds $M$, et al. Variation in Volatile Leaf Oils of Seven Eucalyptus Species Harvested from Zerniza Arboreta (Tunisia). Chem Biodivers. 2011;8(2):362-72.

37. Elaissi A, Moumni S, Roeleveld K, Khouja ML. Chemical Characterization of Five Tunisian Eucalyptus Essential Oils Species. Chem Biodivers. 2020;17(1):e1900378

38. Elaissi A, Salah KH, Mabrouk S, Larbi KM, Chemli R, Harzallah-Skhiri F. Antibacterial activity and chemical composition of 20 Eucalyptus species' essential oils. Food Chem. 2011;129(4):1427-34

39. Elaissi A, Rouis Z, Mabrouk S, et al. Correlation Between Chemical Composition and Antibacterial Activity of Essential Oils from Fifteen
Eucalyptus Species Growing in the Korbous and Jbel Abderrahman Arboreta (North East Tunisia). Molecules. 2012;17(3):3044-57.

40. Council of Europe. European pharmacopoeia. 10th ed. Strasbourg: Council of Europe; 2020.

41. John Wiley \& Sons. Wiley Registry ${ }^{\circledR}$ of Mass Spectral Data/NIST Spectral Data/CD Rom, $11^{\text {th }}$ edition. Hoboken, NJ: Wiley-Blackwell; 2014.

42. Ponce AG, Fritz R, Valle C, Roura SI. Antimicrobial activity of essential oils on native microbial population of organic Swiss Chard. LWT - Food Sci Technol. 2003:36:679-84.

43. Schwarz S, Silley P, Simjee S, et al. Editorial: assessing the antimicrobial susceptibility of bacteria obtained from animals. J Antimicrob Chemother. 2010;65(4):601-4.

44. Moumni S, Elaissi A, Trabelsi A, et al. Correlation between chemical composition and antibacterial activity of some Lamiaceae species essential oils from Tunisia. BMC Complement Med Ther. 2020;20(1):103

45. Schaechter M, Medoff G, Eisenstein BI, Flandrois J-P. Microbiologie et pathologie infectieuse (Français) Broché - 12 février 1999. Paris: De Boeck University; 1999.

46. Dramane S, Koné M, Kamanzi K. Evaluation des Activités Antimicrobiennes et Anti-Radicaux Libres de Quelques Taxons Bioactifs de Côte D'ivoire. Eur J Sci Res. 2010;40:307-17.

47. Foudil-Cherif Y, Meklati BY, Verzera A, Mondello L, Dugo G. Chemical Examination of Essential Oils from the Leaves of Nine Eucalyptus Species Growing in Algeria. J Essent Oil Res. 2000;12(2):186-91.

48. Fouad R, Bousta D, Lalami AEO, et al. Chemical Composition and Herbicidal Effects of Essential Oils of Cymbopogon citratus (DC) Stapf, Eucalyptus cladocalyx, Origanum vulgare L and Artemisia absinthium L. cultivated in Morocco. J Essent Oil Bear PI. 2015;18(1):112-123.

49. Farah A, Fechtal M, Chaouch A. Effet de I'hybridation interspécifique sur la teneur et la composition chimique des huiles essentielles d'eucalyptus cultivés au Maroc. Biotechnol Agron Soc Environ. 2002;6(3):7163-9.

50. Ben Hassine D, Ben Ismail H, Chokri J, Khouja ML, Abderrabba M. Chemical composition of some Tunisian Eucalyptus essential oils as obtained by hydrodistillation using Clevenger type apparatus. Biosci Biotech Re Asia. 2010;7:647-56.

51. Zrira SS, Benjilali BB, Fechtal MM, Richard HH. Essential Oils of Twenty-seven Eucalyptus Species Grown in Morocco. J Essent Oil Res. 1992;4(3):259-64

52. Bignell CM, Dunlop PJ, Brophy JJ, Jackson JF. Volatile Leaf Oils of some Queensland and Northern Australian Species of the Genus Eucalyptus. (Series II). Part I. Subgenus Symphyomyrtus, Section Adnataria: (a) Series Oliganthae, (b) Series Ochrophloiae, (c) Series Moluccanae, (d) Series Polyanthemae, (e) Series Paniculatae, ( $f$ ) Series Melliodorae and (g) Series Porantheroideae. Flavour Fragr J. 1997:12(1):19-27.

53. Esfahanianfard N, Sefidkon F, Bakhshi Khaniki G. Seasonal variation in the essential oil content and composition of three Eucalyptus species (Eucalyptus melliodora Cunn. ex Schauer, E. kingsmilli Maiden \& Blakely and E. dundasii Maiden) from South Iran. Iran J of Med Arom Plants. 2011:27:97-126.

54. Cimanga K, Kambu K, Tona L, et al. Correlation between chemical composition and antibacterial activity of essential oils of some aromatic medicinal plants growing in the Democratic Republic of Congo. J Ethnopharmacol. 2002;79(2):213-20.

55. Bignell CM, Dunlop PJ, Brophy JJ. Volatile leaf oils of some Queensland and northern Australian species of the genus Eucalyptus (series II). Part II. Subgenera (a) Blakella, (b) Corymbia, (c) Unnamed, (d) Idiogenes, (e) Monocalyptus and (f) Symphyomyrtus. Flavour Fragr J. 1997:12(4):277-284.

56. Filomeno CA, Barbosa LCA, Pereira JL, Pinheiro AL, Fidêncio PH, Montanari RM. The Chemical Diversity of Eucalyptus spp. Essential Oils from Plants Grown in Brazil. Chem Biodivers. 2016;13(12):1656-1665.

57. Sartorelli P, Marquioreto AD, Amaral-Baroli A, Lima MEL, Moreno PRH. Chemical composition and antimicrobial activity of the essential oils from two species of Eucalyptus. Phytother Res. 2007;21(3):231-3.

58. Liu XC, Liu QZ, Shi WP, Liu ZL. Evaluation of insecticidal activity of the essential oil of Eucalyptus robusta Smith leaves and its constituent compound against overwintering Cacopsylla chinensis (Yang et Li) (Hemiptera: Psyllidae). J Entomol Zool Stud. 2014;2(4):27-31. 
59. Benayache S, Benayache F, Benyahia S, Chalchat J-C, Garry R-P. Leaf Oils of some Eucalyptus Species Growing in Algeria. J Essent Oil Res. 2001;13(3):210-3.

60. Southwell IA. Variation in the leaf oil of Eucalyptus punctata. Phytochemistry. 1973;12(6):1341-3.

61. Dellacassa E, Menéndez P, Moyna P, Soler E. Chemical composition of Eucalyptus essential oils grown in Uruguay. Flavour Fragr J. 1990;5(2):91-5.

62. Bignell CM, Dunlop PJ, Brophy JJ. Volatile leaf oils of some south-western and southern Australian species of the genus Eucalyptus (series I). Part XVIII. A. Subgenus monocalyptus. B. Subgenus symphyomyrtus: (i) section guilfoyleanae; (ii) section bisectaria, series accedentes, series occidentales, series levispermae, series loxophlebae, series macrocarpae, series orbifoliae, series calycogonae; (iii) section dumaria, series incrassatae and series ovulares. Flavour Fragr J. 1997;12(6):423-432.

63. Bouzabata A, Bighelli A, Abed L, Casanova J, Tomi F. Composition and Chemical Variability of Eucalyptus bosistoana Essential Oil from Algerian Sahara. Nat. Prod. Commun. 2014;9(5):1934578X1400900.

64. Faria JMS, Lima AS, Mendes MD, et al. Eucalyptus From Mata Experimental do Escaroupim (Portugal): Evaluation Of The Essential Oil Composition From Sixteen Species. Acta Hortic. 2011;925:61-6.

65. Moudachirou M, Gbenou JD, Chalchat JC, Chabard JL, Lartigue C. Chemical composition of essential oils of Eucalyptus from Benin: Eucalyptus citriodora and E. camaldulensis. Influence of location, harvest time, storage of plants and time of steam distillation. J Essent Oil Res. 1999;11:109-118.

66. Bhatti HN, labal Z, Chatha SAS, Bukhari IH. Variations in Oil Potential and Chemical Composition of Eucalyptus crebra Among Different Districts of Punjab-Pakistan. Int J Agric Biol. 2007;9(1):136-8.

67. Doran JC, Bell RE. Influence of non-genetic factors on yield of monoterpenes in leaf oils of Eucalyptus camaldulensis. New For. 1994;8(4):363-79.

68. Barra A. Factors Affecting Chemical Variability of Essential Oils: A Review of Recent Developments. Nat. Prod. Commun. 2009;4(8):1934578X0900400.

69. Padovan A, Webb H, Mazanec R, et al. Association genetics of essential oil traits in Eucalyptus loxophleba: explaining variation in oil yield. Mo Breeding 2017;37.

70. Echeverrigaray S, Agostini G, Atti-Serfini L, Paroul N, Pauletti GF, dos Santos AC. Correlation between the chemical and genetic relationships among commercial thyme cultivars. J Agric Food Chem. 2001;49(9):4220-3.

71. Angioni A, Barra A, Cereti E, et al. chemical composition, plant genetic differences, antimicrobial and antifungal activity investigation of the essential oil of Rosmarinus officinalis L. J Agric Food Chem. 2004;52(11):3530-5. https://doi.org/10.1021/jf049913t.

72. Filomeno CA, Barbosa LCA, Teixeira RR, et al. Corymbia spp. and Eucalyptus spp. essential oils have insecticidal activity against Plutella xylostella. Ind Crops Prod. 2017:109:374-383.

73. Alfian Z, Taufik M, Marpaung H, Sibarani IJ. Analysis of composition and sineol determination of eucalyptus oil (Eucalyptus Robusta) from PT. Toba Pulp Lestari Used Gc-Ms Method. Int J Appl Chem (IJAC). 2018;14(3):255-262

74. Elaissi A, Chemli R, Harzallah-Skhiri F, Khouja ML. Variation in Volatile Leaf Oils of Seven Eucalyptus Species Harvested from Zerniza Arboreta (Tunisia). Chem Biodivers. 2011;8(2):362-72.
75. Elaissi Ameur, Medini Hanene, Rouis Zied, Khouja Mohamed Larbi, Chemli Rachid, Harzallah-Skhiri Fethia. Impact of geographic's variation On The essential oil yield and chemical composition of three Eucalyptus species acclimated In Tunisia. J Exp Biol Agric Sci. 2015:324-336.

76. Nikbakht MR, Rahimi-Nasrabadi M, Ahmadi F, Gandomi H, Abbaszadeh S, Batooli $\mathrm{H}$. The Chemical Composition and in vitro Antifungal Activities of Essential Oils of Five Eucalyptus Species. J Essent Oil Bear PI. 2015;18(3):666-77.

77. Griffin SG, Wyllie SG, Markham JL, Leach DN. The role of structure and molecular properties of terpenoids in determining their antimicrobial activity. Flavour Fragr J. 1999;14(5):322-32.

78. Pitarokili D, Tzakou O, Loukis A, Harvala C. Volatile Metabolites from Salvia fruticosa as Antifungal Agents in Soilborne Pathogens. J Agric Food Chem. 2003;51(11):3294-301.

79. Sonboli A, Babakhani B, Mehrabian AR. Antimicrobial Activity of Six Constituents of Essential Oil from Salvia. Z Naturforsch. 2006;(61c):160-164.

80. Hendry ER, Worthington T, Conway BR, Lambert PA. Antimicrobial efficacy of eucalyptus oil and 1,8-cineole alone and in combination with chlorhexidine digluconate against microorganisms grown in planktonic and biofilm cultures. J Antimicrob Chemother. 2009;64(6):1219-25.

81. Miguel M, Gago C, Antunes M, et al. Antibacterial, Antioxidant, and Antiproliferative Activities of Corymbia citriodora and the Essential Oils of Eight Eucalyptus Species. Medicines. 2018;5(3):61.

82. Hammer KA, Carson CF, Riley TV. Antifungal activity of the components of Melaleuca alternifolia (tea tree) oil. J Appl Microbiol. 2003;95(4):853-60.

83. Inouye S, Takizawa T, Yamaguchi H. Antibacterial activity of essential oils and their major constituents against respiratory tract pathogens by gaseous contact. J Antimicrob Chemother. 2001;47(5):565-73.

84. Bakkali F, Averbeck S, Averbeck D, Idaomar M. Biological effects of essential oils - A review. Food Chem Toxicol. 2008;46(2):446-75.

85. Hyldgaard M, Mygind T, Meyer RL. Essential oils in food preservation: mode of action, synergies, and interactions with food matrix components. Front Microbiol. 2012;3:12.

86. de Aguiar FC, Solarte AL, Tarradas C, et al. Antimicrobial activity of selected essential oils against Streptococcus suis isolated from pigs Microbiologyopen. 2018;7(6):e00613.

87. Swamy MK, Akhtar MS, Sinniah UR. Antimicrobial Properties of Plant Essential Oils against Human Pathogens and Their Mode of Action: An Updated Review. Evid Based Complement Alternat Med. 2016;2016.3012462

88. Ezzeddine NBH-B, Abdelkéfi MM, Aissa RB, Chaabouni MM. Antibacterial Screening of Origanum majorana L. Oil from Tunisia. J Essent Oil Res. 2001;13(4):295-297.

89. Raut JS, Karuppayil SM. A status review on the medicinal properties of essential oils. Ind Crops Prod. 2014;62:250-64.

90. Karl K, Alexander P, Bernard I, Hildegunde W, Norbert W. Antibacterial and Antifungal Properties of Essential Oil Components. J Essent Oil Res. 1989;1(3):119-28.

\section{Publisher's Note}

Springer Nature remains neutral with regard to jurisdictional claims in published maps and institutional affiliations.

Ready to submit your research? Choose BMC and benefit from

- fast, convenient online submission

- thorough peer review by experienced researchers in your field

- rapid publication on acceptance

- support for research data, including large and complex data types

- gold Open Access which fosters wider collaboration and increased citations

- maximum visibility for your research: over $100 \mathrm{M}$ website views per year

At BMC, research is always in progress.

Learn more biomedcentral.com/submissions 